OPEN ACCESS

Edited by:

Santanu Bose,

Washington State University,

United States

Reviewed by:

Nathalie Grandvaux,

Université de Montréal, Canada

Darius Widera,

University of Reading, United Kingdom

*Correspondence:

Meilin Jin

jm/8328@126.com;

jinmeilin@mail.hzau.edu.cn

Received: 22 January 2017 Accepted: 03 May 2017

Published: 22 May 2017

Citation:

Wang S, Sun X, Yi C, Zhang D, Lin X, Sun $X$, Chen $H$ and Jin M (2017)

AGO2 Negatively Regulates Type I Interferon Signaling Pathway by Competition Binding IRF3 with

$\mathrm{CBP} / \mathrm{p} 300$

Front. Cell. Infect. Microbiol. 7:195. doi: 10.3389/fcimb.2017.00195

\section{AGO2 Negatively Regulates Type I Interferon Signaling Pathway by Competition Binding IRF3 with $\mathrm{CBP} / \mathrm{p} 300$}

\author{
Shengyu Wang ${ }^{1,2}$, Xin Sun ${ }^{1,2}$, Chenyang $\mathrm{Yi}^{1,2}$, Dan Zhang ${ }^{1,2}$, Xian Lin ${ }^{1,2}$, Xiaomei Sun ${ }^{2}$, \\ Huanchun Chen 1, 2, 3,4 and Meilin Jin 1,2,3,4* \\ 1 State Key Laboratory of Agricultural Microbiology, Huazhong Agricultural University, Wuhan, China, ${ }^{2}$ Laboratory of Animal \\ Virology, College of Veterinary Medicine, Huazhong Agricultural University, Wuhan, China, ${ }^{3}$ Key Laboratory of Development of \\ Veterinary Diagnostic Products, Ministry of Agriculture, College of Veterinary Medicine, Huazhong Agricultural University, \\ Wuhan, China, ${ }^{4}$ The Cooperative Innovation Center for Sustainable Pig Production, Wuhan, China
}

Viral infection triggers a series of signaling cascades and host innate immune responses, including interferon (IFN) production, which depends on coordinated activity of multiple transcription factors. IFN regulatory factor 3 (IRF3) and transcriptional coactivator CREB binding protein (CBP) and/or p300 are core factors that participate in transcriptional complex formation in the nucleus. In general, cells balance the production of IFNs through suppressive and stimulative mechanisms, but viral infections can disrupt such equilibrium. This study determined that H5N1 viral infection reduced the distribution of human argonaute 2 (AGO2) in A549 cell nucleus. AGO2 did not block phosphorylation, nuclear translocation, and DNA binding ability of IRF3 but inhibited its association with CBP. Therefore, this newly revealed mechanism shows that cellular response leads to transfer of AGO2 from cell nucleus and promotes IFN- $\beta$ expression to increase host survival during viral infection.

Keywords: AGO2, negative regulation, type I interferon, IRF3, CBP/p300

\section{INTRODUCTION}

Viral infection results in activation of innate and multistep immune responses. These responses require recognition of viral infections, activation of multiple signal transduction cascades, and transcription of antiviral genes (Akira et al., 2006; Katze et al., 2008; Goubau et al., 2013). Interferon beta (IFN- $\beta$ ) is one of the most important proteins and is a critical component of innate immune response; most cells of the body secrete this type of molecule (Akira et al., 2006; Ivashkiv and Donlin, 2014). During cell infection, viruses are recognized by intracellular pattern recognition receptors (PRRs), which include Toll-like receptors, retinoic acid-inducible gene I (RIG-I)-like receptors and nucleotide-binding oligomerization domain like receptors. PRRs activate innate immune signaling pathways and increase activities of transcription factors (Akira et al., 2006; Gilliet et al., 2008; Chiang et al., 2014; Wu and Chen, 2014). These transcription factors include IFN regulatory factor 3 (IRF3), nuclear factor kappa $\mathrm{B}$, activator protein 1 , and the coactivator CREB binding protein $(\mathrm{CBP})$ and/or $\mathrm{p} 300$. Together, these transcription factors can form complexes that bind to regulatory domains of the IFN- $\beta$ promoter and induce transcription of IFN- $\beta$ (Yoneyama et al., 1998; Gough et al., 2012; Ivashkiv and Donlin, 2014). 
IFN- $\beta$ is tightly regulated in many ways, and its aberrant secretion can trigger diseases, such as multiple sclerosis and systemic lupus erythematosus. Regulation of IRF3, a key protein in the IFN- $\beta$ pathway, includes important positive and negative mechanisms (Gonzalez-Navajas et al., 2012; Ivashkiv and Donlin, 2014; Ysebrant de Lendonck et al., 2014). The positive mechanisms comprise increased expression and activation of IRF3, and the negative ones involves its decreased expression and inactivation (Servant et al., 2002; Ysebrant de Lendonck et al., 2014; Wang et al., 2015; Meng et al., 2016). IFN- $\beta$ expression is also regulated by formation of a transcriptional complex containing IRF3 and CBP/p300 (Yoneyama et al., 1998; Servant et al., 2002).

IRF3 is the most important factor in regulation of viral induced IFN- $\beta$ activation. In general, IRF3 is found in the cytoplasm in latent form (Ysebrant de Lendonck et al., 2014). When viruses expose pathogen-associated molecular patterns and are recognized by PRRs, IRF3 is activated to promote antivirus reaction (Akira et al., 2006; Chiang et al., 2014; Ivashkiv and Donlin, 2014). Activation of IRF3 includes C-terminal region phosphorylation, dimerization, and translocation to the nucleus (Servant et al., 2002; Ysebrant de Lendonck et al., 2014).

Studies extensively investigated the mechanisms underlying phosphorylation-induced activation of IRF3 (Lin et al., 1998, 1999; Yoneyama et al., 1998; Servant et al., 2001, 2003; Mori et al., 2004; Chen et al., 2008; Clement et al., 2008; Takahasi et al., 2010). IRF3 is phosphorylated on multiple phosphorylation acceptor (phospho-acceptor) sites. Previous studies showed that phosphorylation of C-terminal phospho-accepter clusters (Ser385-Ser386 and Ser396-Ser398-Ser402-Thr404-Ser405) plays important role in activation of IRF3 (Lin et al., 1998, 1999; Yoneyama et al., 1998; Servant et al., 2003; Mori et al., 2004). Other research also showed that phosphorylation of Ser339 on IRF3 is involved in stabilizing IRF-3, and mutation of Ser339 can abrogate CBP association, and dimerization (Saitoh et al., 2006; Clement et al., 2008). However, Ser339 mutation does not affect gene transactivation as long as Ser396 is available for phosphorylation (Clement et al., 2008). Previously published data indicated that Ser386 and Ser396 play important roles in IRF3 activity, and Ser339 is not integrant under physiological conditions.

Transcriptional coactivators CBP and p300 are critical regulators of metazoan gene expression (Lin et al., 2001; Suhara et al., 2002). Transcriptional coactivators associate with different DNA-bound transcription factors through small conserved domains (Lin et al., 2001). A compactly folded 46-residue domain in CBP serves as the IRF3 binding domain (IBiD), and interaction occurs at the $\mathrm{C}$ terminus domain of IRF3 (Lin et al., 2001). Activated IRF3 interacts with coactivator CBP/p300 and initiates transcription of IFN- $\beta$ (Yoneyama et al., 1998; Suhara et al., 2002; Reily et al., 2006; Ysebrant de Lendonck et al., 2014). Phosphorylation at Ser386 and Ser396 plays significant roles in IRF3 activation and its interaction with CBP (Chen et al., 2008; Takahasi et al., 2010). Following phosphorylation and dimerization, IRF3 translocates to the nucleus and recruits CBP and/or p300 for full activation (Yoneyama et al., 1998; Suhara et al., 2002; Ysebrant de Lendonck et al., 2014; Song et al., 2016).
Then, this complex binds to PRD I/III in the IFN- $\beta$ promoter for transcription activation and IFN- $\beta$ production (Weaver et al., 1998).

Human argonaute 2 (AGO2) is a multifunctional protein that interact with many molecules (Hock and Meister, 2008; Martinez and Gregory, 2013). Recent studies on the structure of AGO2 have revealed the four core domains including $\mathrm{N}$ domain, PAZ domain, MID domain, and PIWI domain (Kuhn and Joshua-Tor, 2013; Ye et al., 2015). AGO2 is a key regulator and activator that performs specific siRNA/miRNA-dependent and -independent functions. This protein also interacts with Dicer, TAR RNA binfing protein (TRBP) and PACT, which are required to construct the RNA-induced silencing complexloading complex and to process precursor miRNAs into mature miRNAs (Chendrimada et al., 2005; Martinez and Gregory, 2013; Ye et al., 2015). AGO2 also inhibits translation initiation via interaction with eukaryotic initiation factor 6 (eIF6) and prevents recruitment of the translation initiation factor eIF4-E by binding to 7-methylguanosine cap (Chendrimada et al., 2007; Kiriakidou et al., 2007). AGO2 binds to AU element of 3'-untranslated region of TNF (i.e., TNF-alpha) mRNA and upregulates translation under serum starvation (Vasudevan and Steitz, 2007). AGO2 is also normally located on euchromatin instead of heterochromatin, and once combined with CTCF/CP190, it can inhibit related target gene expression through CTCF/CP190dependent Fab-8 insulation (Moshkovich et al., 2011). Studies on cellular functions of AGO2 should thus be continued.

Previous studies showed that the proteins associated with RNA interference (RNAi) pathway may influence viral replication. For instance, PACT enhances the function of RIG-I, and TRBP influences PKR, these phenomena can affect innate immunity and viral proliferation (Cosentino et al., 1995; Kok et al., 2011; Kim et al., 2014). Dicer functions as effector and sensor by cleaving viral double-stranded RNAs and by activating downstream signaling or effector systems that generate relatively more robust and amplified antiviral responses (Ahmad and Hur, 2015). Dicer also reduces influenza viral replication, which is siRNA/miRNA independent (Matskevich and Moelling, 2007). This study further investigated AGO2 function during viral infection. This study reveals that AGO2 participates in negative regulation of IFN- $\beta$ signaling pathway in a novel manner, inhibiting formation of transcription initiation complex and consequent IFN- $\beta$ production.

\section{MATERIALS AND METHODS}

\section{Cell Culture and Transfection}

Madin-Darby canine kidney (MDCK) cells were obtained from the American Type Culture Collection (ATCC) and maintained in Dulbecco's minimal essential medium (DMEM; Invitrogen, Carlsbad, CA, USA) with $10 \%$ fetal bovine serum (FBS; PAN biotech, Auckland, New Zealand) and $5 \% \mathrm{CO}_{2}$ at $37^{\circ} \mathrm{C}$. Human embryonic kidney (HEK293T) cells were maintained in RPMI 1640 medium (HyClone, China) with 10\% FBS, and human type II alveolar epithelial (A549) cells were propagated in Ham's F12K medium (F-12, HyClone, China) with 10\% FBS and 5\% $\mathrm{CO}_{2}$ at $37^{\circ} \mathrm{C}$. 
For the transient overexpression of specific proteins, cells were transfected using Lipfection2000 (Invitrogen) and analyzed at $36 \mathrm{~h}$ or $48 \mathrm{~h}$ post transfection. For gene silencing, AGO2 siRNA (siAGO2) and control siRNA (siNC) were obtained from Transheep (Transheep, Shanghai, China). Cells were transfected with siRNAs using Lipfection 2000 following the manufacturer's protocol at a final concentration of $100 \mathrm{nM}$.

\section{Antibodies and Plasmids}

The antibodies used in this study were sourced from the following: mouse monoclonal Flag antibody was from Sigma (MO, USA); mouse monoclonal HA antibody was from MBL (Japan); rabbit polyclonal HA antibody and rabbit polyclonal IRF3 antibody were from ABclonal Biotechnology (China); rabbit polyclonal Ser396 phosphorylated IRF3 antibody was from Merck Millipore (Germany); rabbit polyclonal Ser386 phosphorylated IRF3 antibody, mouse monoclonal AGO2 antibody [2E12-1C9], rabbit monoclonal AGO2 antibody [EPR10410] and rabbit monoclonal LaminA/C antibody [EPR4100] were from Abcam (Cambridge, UK); CBP (D6C5) Rabbit mAb and Myc-Tag (9B11) Mouse mAb were from Cell Signaling Technology (USA); mouse anti- $\beta$-actin polyclonal antibody, mouse anti- $\beta$-tubulin polyclonal antibody and mouse anti-GAPDH polyclonal antibody were from BioPM (Wuhan, China); fluorescein isothiocyanate (FITC)-labeled goat anti-mouse secondary antibody, Cy3-labeled goat antirabbit secondary antibody and horseradish peroxidase (HRP) conjugated secondary antibodies were from PKR (China).

Flag-RIG-I, Flag-VISA, Flag-TBK-1 and HA-IRF3 expression plasmids and a luciferase (Luc) reporter plasmid for the IFN$\beta$ promoter (IFN- $\beta$-Luc) were kindly provided by Zhengfan Jiang (Peking University, China) (You et al., 2009). A Renilla control plasmid (pGL4.75 hRluc/CMV, where CMV is a cytomegalovirus) (Promega) was used to control for the cell number and transfection efficiency. HA-AGO2 and FlagAGO2 was amplified from HEK293T cDNA and inserted into pCAGGS-HA expression vector and $\mathrm{p} 3 \times \mathrm{FLAG}-\mathrm{CMV}-$ 14 expression vector. Flag-IRF3 was cloned from HA-IRF3 and inserted into p $3 \times$ FLAG-CMV-14 expression vector. FlagRIG-I-N, Flag-IRF3-5D, FLAG-IRF3(1-197), Flag-IRF3(198427), Flag-IRF3-5D(198-427), and Myc-IBiD were generated as previously described and were cloned into pCAGGS-HA expression vector, $\mathrm{p} 3 \times \mathrm{FLAG}-\mathrm{CMV}-14$ expression vector or pCMV-C-Myc expression vector (Lin et al., 1998, 1999, 2001; Yoneyama et al., 2005). The four domain of AGO2 were amplified from $\mathrm{HA}-\mathrm{AGO} 2$ and inserted into pCAGGS-HA expression vector (HA-AGO2-N, HA-AGO2-PAZ, HA-AGO2-MID, and HA-AGO2-PIWI) as previously described (Kuhn and JoshuaTor, 2013). The MID deleted AGO2 were cloned from HAAGO2 and inserted into pCAGGS-HA expression vector (HAAGO2-MIDdel). All plasmids constructs were verified by DNA sequencing.

\section{$\mathrm{TCID}_{50}$ Assays}

Cell supernatants containing the virus were serially diluted 10 fold with DMEM and applied in quadruplicate to $2 \times 10^{4} \mathrm{MDCK}$ cells/well in a 96-well plate. On the fifth day post infection, the viral titer was determined by observing the cytopathogenic effect and was confirmed by hemagglutination. The TCID 50 was determined based on the Reed-Muench method as described previously (Ramakrishnan, 2016).

\section{Influenza Virus Preparation and Infection of Cells}

Wild-type H5N1 virus A/Hubei/hangmei01/2006 (H5N1) and Sendai virus $(\mathrm{SeV})$ were grown in 10-day-old fertilized eggs. The working stocks were stored at $-80^{\circ} \mathrm{C}$ as live viruses or after inactivation by formaldehyde treatment. The viral titer of H5N1 was measured using the Reed-Muench method (Ramakrishnan, 2016). H5N1 virus experiments were performed in Biosafety Level 3 facilities at the State Key Laboratory of Agricultural Microbiology, College of Veterinary Medicine, Huazhong Agricultural University, China.

For H5N1 infection, A549 cells were washed three times in F12 to remove FBS and then incubated with influenza virus diluted in F-12 for $1 \mathrm{~h}$ at $37^{\circ} \mathrm{C}$. After $1 \mathrm{~h}$, the cells were washed and maintained in F-12 with 1\% FBS for the indicated times. For IFN$\beta$ expression, HEK293T cells and A549 cells were stimulated with $\mathrm{SeV}$ and analyzed at $3,6,12$, or $24 \mathrm{~h}$ later.

\section{Luciferase Reporter Assay}

HEK293T cells in 12-well plates were transfected with $0.5 \mu \mathrm{g}$ of IFN- $\beta$-Luc and $0.01 \mu \mathrm{g}$ of pGL4.75 hRluc/CMV with 0.5 , $1 \mu \mathrm{g}$, and/or $2 \mu \mathrm{g}$ of AGO2 expressing plasmids; $24 \mathrm{~h}$ post transfection, cells were stimulated with $\mathrm{SeV}$ for $12 \mathrm{~h}$ and then lysed in $200 \mu \mathrm{l}$ of passive lysis buffer (PLB; Promega). HEK293T cells in 12-well plates were transfected with siAGO2 and, 36 $\mathrm{h}$ later, the cells were transfected with $0.5 \mu \mathrm{g}$ of IFN- $\beta$-Luc and $0.01 \mu \mathrm{g}$ of pGL4.75 hRluc/CMV; after another $24 \mathrm{~h}$ post transfection, cells were stimulated with $\mathrm{SeV}$ for $12 \mathrm{~h}$ and then lysed in $200 \mu \mathrm{l}$ of passive lysis buffer. HEK293T cells in 12-well plates were transfected with $0.5 \mu \mathrm{g}$ of IFN- $\beta$-Luc; $0.01 \mu \mathrm{g}$ of pGL4.75 hRluc/CMV; $0.5 \mu \mathrm{g}$ of RIG-I, RIG-I-N, VISA, TBK1, IRF3, or IRF3-5D; and $2 \mu \mathrm{g}$ of the AGO2 expressing plasmids using $6 \mu$ l of Lipofectamine 2000. The cells were incubated for 24 $\mathrm{h}$ and then lysed in $200 \mu \mathrm{l}$ of passive lysis buffer. Luciferase and Renilla activities were assessed using a Dual-Luciferase Assay Kit (Promega).

\section{Quantitative RT-PCR}

Total cellular RNA was extracted using TRIzol (Life Technologies, USA) and treated with DNase using RQ RNasefree DNase (Promega, China) prior to cDNA production. The cDNA was reverse-transcribed from $1 \mu \mathrm{g}$ of total RNA using oligo(dT) primers according to the manufacturer's protocol (TaKaRa, China). Quantitative RT-PCR was carried out using SYBR Green Master Mix (Roche) and specific primer sets (Table 1). Amplification reactions were performed under the following conditions: $2 \mathrm{~min}$ at $50^{\circ} \mathrm{C}, 10 \mathrm{~min}$ at $95^{\circ} \mathrm{C}, 40$ cycles for $15 \mathrm{~s}$ at $95^{\circ} \mathrm{C}$, and $1 \mathrm{~min}$ at $60^{\circ} \mathrm{C}$. Relative transcript levels were calculated using the $\Delta \Delta \mathrm{Ct}$ method as specified by the manufacturer. 
TABLE 1 | List of primers for different genes.

\begin{tabular}{lll}
\hline Gene name & Forward primer sequence & Reverse primer sequence \\
\hline GAPDH & GACAACTTGGTATCGTGGAA & CCAGGAAATGAGCTTGACA \\
IFN- $\beta$ & CTCTCCTGTTGTGCTCTCC & GTCAAAGTCATCCTGTCCTTG \\
Mx1 & GGTGGTCCCCAGTAATGTGG & CGTCAAGATTCCGATGGTCCT \\
IFIT1 & GCGCTGGGTATGCGATCTC & CAGCCTGCCTTAGGGGAAG \\
ISG15 & TGGACAAATGCGACGAACCTC & TCAGCCGTACCTCGTAGGTG \\
OAS1 & AGCTTCGTACTGAGTCGCTC & CCAGTCAACTGACCCAGGG \\
STAT1 & CGGCTGAATTCGGCACCT & CAGTAACGATGAGAGGACCCT \\
AGO2 & GTTGACGGCAGGAAGATCT & AGGACACCCACTTGATGGACA \\
NP & CAGCGTTCAGCCCACTTCT & GGGTTCGTTCCTITCGTC
\end{tabular}

All of the sequence are from $5^{\prime}-3^{\prime}$.

\section{Immunoprecipitation}

Cells were lysed in RIPA lysis buffer (CST, USA) containing protease inhibitors (Calbiochem) for $30 \mathrm{~min}$ on ice and were then centrifuged at $12,000 \mathrm{rpm}$ for $15 \mathrm{~min}$. The supernatant was incubated with antibody for $1 \mathrm{~h}$ at $4^{\circ} \mathrm{C}$ and the lysateantibody complexes were incubated with Protein A/G PLUSAgarose (Santa Cruz Biotechnology, Europe) overnight at $4^{\circ} \mathrm{C}$. The precipitated agarose was washed four times with lysis buffer to remove nonspecific binding. The immune complex was eluted with $2 \times$ SDS Loading buffer and boiled, separated on SDSPAGE, and analyzed by Western analysis. The Bradford assay was used for protein quantification.

\section{Immunofluorescence and Microscopy}

To visualize the subcellular localization of IRF3 and AGO2, cells were mock infected or infected with $\mathrm{SeV}$. The cells were then fixed with $4 \%$ paraformaldehyde for $15 \mathrm{~min}$ and permeabilized with $0.1 \%$ Triton X-100 for $15 \mathrm{~min}$ at room temperature. After three washes with phosphate-buffered saline (PBS), the cells were blocked with PBS containing $3 \% \mathrm{BSA}$ at $37^{\circ} \mathrm{C}$ for $1 \mathrm{~h}$. The cells were then incubated separately with rabbit polyclonal IRF3 antibody (1:100) and mouse monoclonal AGO2 antibody (1:200) overnight at $4^{\circ} \mathrm{C}$. Subsequently, the cells were treated with FITC-labeled goat anti-mouse secondary antibody and Cy3labeled goat anti-rabbit secondary antibody (1:500) for $1 \mathrm{~h}$ and then stained with DAPI $(1: 1,000$, Beyotime, China) for $15 \mathrm{~min}$ at room temperature. After the samples were washed with PBS, fluorescent images were acquired with a confocal laser scanning microscope (Carl Zeiss, Göttingen, Germany).

\section{Subcellular Fractionation}

For subcellular fractionation, the previously reported protocol was modified and used in this study. A portion of the cells were lysed with RIPA buffer containing protease inhibitor. The samples were frozen and thawed repeatedly and then centrifuged at $12,000 \mathrm{rpm}$ at $4^{\circ} \mathrm{C}$ for $15 \mathrm{~min}$. The supernatants were kept as whole cell samples. The remaining cells from the dishes were lysed with $125 \mu \mathrm{l}$ of hypotonic lysis buffer (10 mM Hepes$\mathrm{NaOH}$ (pH 7.9), $10 \mathrm{mM} \mathrm{KCl}, 1.5 \mathrm{mM} \mathrm{MgCl} 2,0.5 \mathrm{mM}$ betamercaptoethanol) supplemented with protease inhibitor mixture and phosphatase inhibitors, vortexed and then incubated on ice. After 15-20 $\mathrm{min}$, the mixture received an additional $3 \mu \mathrm{l} 10 \%$
NP-40, was vortexed, placed on ice for $2 \mathrm{~min}$ and centrifuged at $16,000 \mathrm{~g}$ at $4^{\circ} \mathrm{C}$ for $10 \mathrm{~min}$. This supernatant was kept as cytoplasmic extract. To prepare nuclear extracts, nuclear pellets were washed two times with $1 \mathrm{ml}$ of ice-cold PBS and were resuspended in $60 \mu \mathrm{l}$ of RIPA buffer as nuclear lysis buffer. The samples were centrifuged at $16,000 \mathrm{~g}$ at $4^{\circ} \mathrm{C}$ for $10 \mathrm{~min}$, and the supernatant was kept as nuclear extract. Proteins were quantified by a Bradford assay, and a western blot was conducted as previously described.

\section{DNA Binding Assay}

The DNA probes labeled with biotin were synthesized by Tsingke BioTech. The sequence of triple repeats of IRF3-recognized and bound ISRE contained biotin-3 $\times$ ISRE-F (biotin-TAGTTTCAC TTTCCCTAGTTTCACTTTCCCTAGTTTCACTTTCCC) and $3 \times$ ISRE-R (GGGAAAGTGAAACTAGGGAAAGTGAAACTAG GGAAAGTGAAACTA), and the sequence of triple repeats of mutated IRF3-recognized and bound ISRE contained biotin$3 \times$ ISRE-mutant-F (biotin-TAGTTTCAGTTTCCCTAGTTTCA

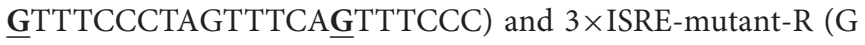

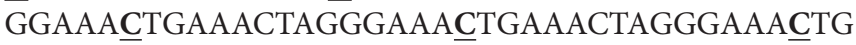
AAACTA) (mutation in bold and underlined). Single strands of DNA were thermally annealed to form dsDNA prior to pull-down experiments. HEK293T cells were transfected with Flag-IRF3 in the absence or presence of HA-AGO2, and cells were infected with $\mathrm{SeV}$ at $24 \mathrm{~h}$ post transfection. Twelve hours later, lysates were mixed with biotinylated DNA probes and incubated for $1 \mathrm{~h}$ at $4^{\circ} \mathrm{C}$. BeaverBeadsTM Streptavidin beads (BEAVER, China) were then added and incubated overnight at $4^{\circ} \mathrm{C}$. The beads were washed four times with PBS and were resolved by $2 \times$ SDS loading buffer for western blot.

\section{Statistical Analyses}

All of the data are shown as mean \pm SD. Statistical analyses were conducted using the Student's $t$ test for two groups. A $p<0.05$ was considered significant.

\section{RESULTS}

\section{AGO2 Increases H5N1 Virus Replication}

AGO2 expression was modified, and H5N1 virus titer in A549 cells was detected to investigate whether AGO2, a key protein in the RNAi pathway, also influences virus propagation. First, siRNA was designed against the human AGO2, and siAGO2 knockdown efficiency was confirmed by quantitative RT-PCR and western blot (Figure 1A). Then, A549 cells were transfected with siAGO2 or nonspecific control siRNA (siNC) and infected with $\mathrm{H} 5 \mathrm{~N} 1$ after 48 h. At $24 \mathrm{~h}$ post infection (h.p.i.), viral NP gene mRNA levels and viral titers were evaluated in $\mathrm{H} 5 \mathrm{~N} 1$ virus infected A549 cells. NP gene mRNA levels were significantly reduced in the siAGO2 group compared with that in control (Figure 1B). Viral titer in siAGO2-treated cells was determined with TCID $_{50}$ assay, and the obtained value was also lower than that of siNC-treated cells at 24 h.p.i. (Figure 1C). These results indicated that $\mathrm{AGO} 2$ knockdown inhibited replication of $\mathrm{H} 5 \mathrm{~N} 1$ virus. The effect of $\mathrm{AGO} 2$ overexpression on viral 
A

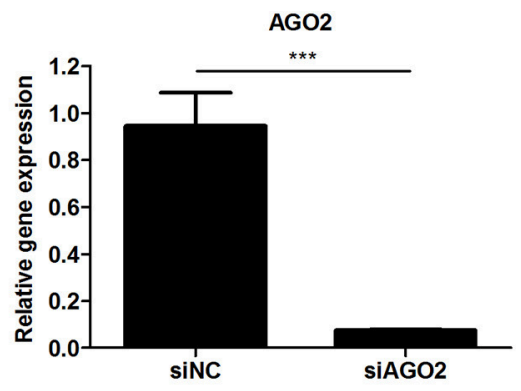

B

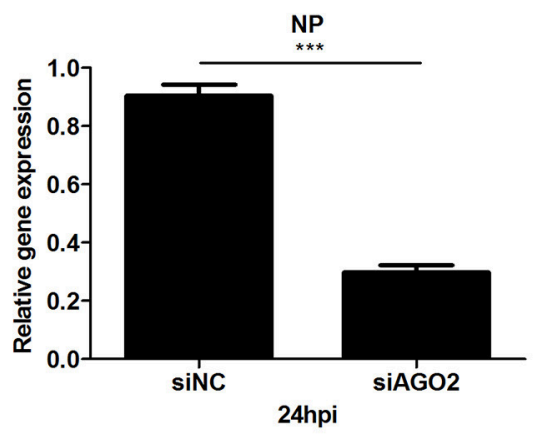

D

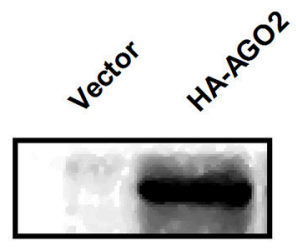

E

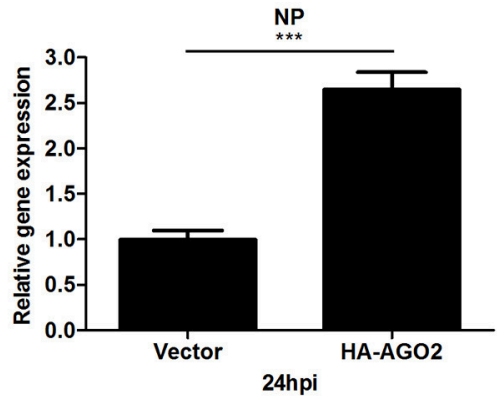

SINC SIAGO2

AGO2

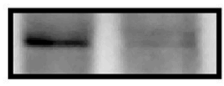

$\beta$-Actin

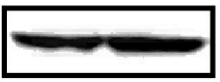

C

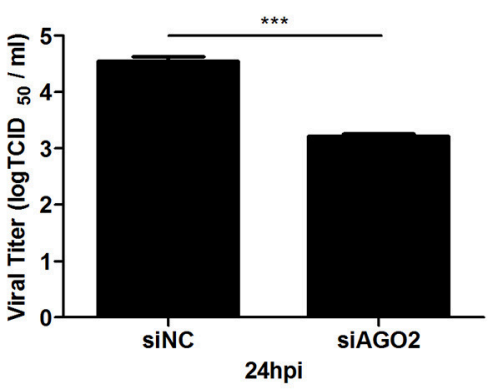

$\mathbf{F}$

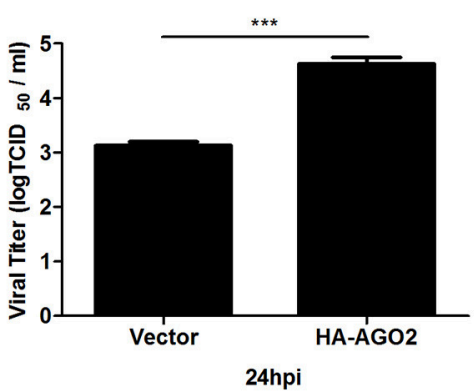

FIGURE 1 | AGO2 promotes proliferation of H5N1 in A549 cells. (A) A549 cells were transfected with siNC or siAGO2. After $48 \mathrm{~h}$, the cells were harvested and examined. Quantitative RT-PCR and western blot were used to assess silencing efficiency. Data are presented as means \pm SD from three independent experiments. (B,C) A549 cells were transfected with siNC or siAGO2. After $48 \mathrm{~h}$, the cells were infected with H5N1. Quantitative RT-PCR for H5N1 NP gene mRNA and TCID50 assays for the virus titer of H5N1 were performed to detect multiplication of the virus at 24 h.p.i. Data are presented as means \pm SD from three independent experiments. (D) A549 cells were transfected with HA-AGO2 and empty vectors, and expressions was detected by western blot. (E,F) A549 cells were transfected with HA-AGO2 and empty vectors. After $48 \mathrm{~h}$, the cells were infected with H5N1. Quantitative RT-PCR for H5N1 NP gene mRNA and TCID 50 assays for the virus titer of $\mathrm{H} 5 \mathrm{~N} 1$ were performed to estimate virus multiplication at 24 h.p.i. Data are presented as means \pm SD from three independent experiments. ${ }^{\star \star \star} P<0.0001$, as determined by a $t$ test.

replication was also determined by transfecting A549 cells with HA-AGO2. Efficacy of AGO2 overexpression was determined by western blot (Figure 1D). As determined by TCID $_{50}$ assay, AGO2-overexpressing groups yielded higher NP gene mRNA level and virus titer than the control group (Figures 1E,F). Protein levels of AGO2 in cells, cytoplasm, and cell nucleus were detected to explore the functional role of AGO2 in virus/host interactions. Results showed reduced protein level of AGO2 in cell nucleus during H5N1 infection (Figures 2A,B). These data indicated that AGO2 promoted replication of $\mathrm{H} 5 \mathrm{~N} 1$ virus, and that its distribution may influence virus/host interactions. 


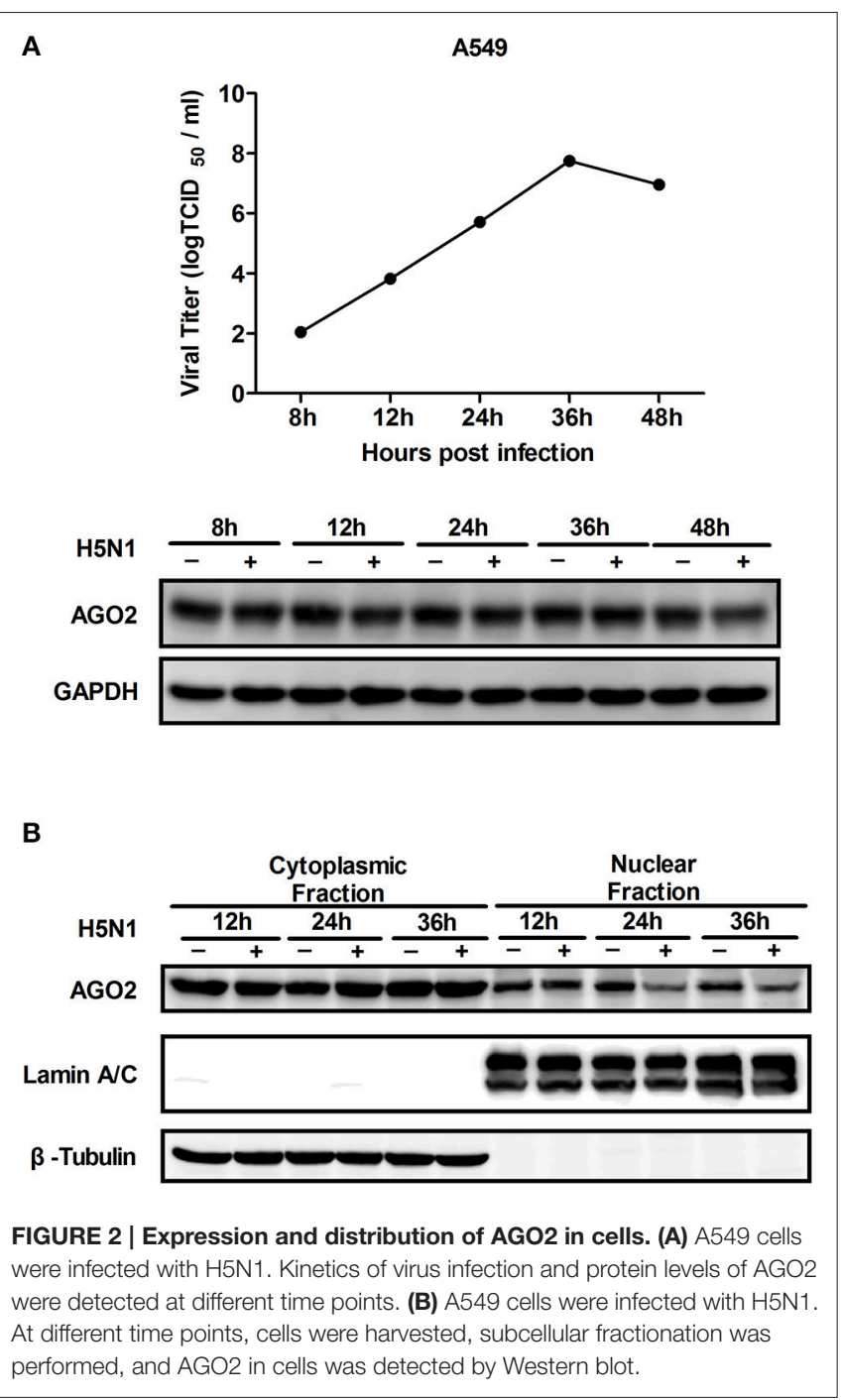

\section{AGO2 Participates in IFN Signaling Pathway}

Previous studies showed that RNAi pathway associated proteins, including PACT and TRBP, regulate IFNs (Cosentino et al., 1995; Kok et al., 2011). This study showed that AGO2 enhances multiplication of $\mathrm{H} 5 \mathrm{~N} 1$ virus and speculated that AGO2 possibly affects IFN signaling pathway. To investigate this hypothesis on AGO2, quantitative RT-PCR was performed, and comparison were made on changes in mRNA expression levels of IFNstimulated genes (ISGs) and IFN- $\beta$ between AGO2 and control knocked down A549 cells stimulated with SeV. Data showed that silencing of AGO2 increased the expression levels of endogenous IFN- $\beta$ and downstream IFIT1 and of ISGs such as Mx1, STAT1, and ISG15 (Figure 3A). Assessment showed significantly reduced endogenous IFN- $\beta$ level with overexpression of AGO2 in SeVsimulated A549 cells (Figure 3B). Double fluorescence reporting system in HEK293T cell showed the same results, and that AGO2 caused dose-dependent inhibition of IFN- $\beta$ promoter activity (Figures 3C,D). These results indicated that AGO2 inhibited expressions of IFN- $\beta$ in both A549 cells and HEK293T cells.

\section{Targets of Inhibitory Effect of AGO2 in Type I IFN Signaling Pathway}

Viral infection also leads to activation of RIG-I and TBK$1 / \mathrm{IKK} \varepsilon$ signaling pathway (Katze et al., 2008; Goubau et al., 2013; Wu and Chen, 2014). HEK293T cells were transfected with an expression construct encoding $\mathrm{AGO} 2$ and overexpressing each of the signaling molecules RIG-I, RIG-I-N, VISA, TBK1, IRF3, or IRF3-5D, along with a luciferase reporter plasmid containing the IFN- $\beta$ promoter (IFN- $\beta$-Luc) and pGL4.75 hRluc/CMV to determine the targets of AGO2 inhibition in IRF3 activation signaling cascade. Results showed that AGO2 suppressed activation of the IFN- $\beta$ promoter; this suppression was mediated by overexpression of RIG-I, RIG-I-N, VISA, TBK1, and IRF3 (Figure 4). AGO2 also inhibited IRF3-5D induced activation of the IFN- $\beta$ promoter (Figure 4). These results confirmed that AGO2 negatively regulates activation of IFN- $\beta$ signaling at the level or downstream of IRF3.

\section{AGO2 Does Not Affect Stability Nor Inhibit Activity of IRF3}

IRF3 is phosphorylated and activated by active TBK-1/IKKe upon viral infection (Yoneyama et al., 1998; Chiang et al., 2014). Phosphorylated IRF3 subsequently forms dimers and translocates to the nucleus, where it interacts with transcription coactivators and promotes IFN- $\beta$ transcription (Chiang et al., 2014; Ysebrant de Lendonck et al., 2014; Song et al., 2016). Ser339 mainly affects protein stability, whereas Ser386/Ser396 play important roles in IRF3 activity (Yoneyama et al., 1998; Servant et al., 2003; Saitoh et al., 2006; Clement et al., 2008). FlagVISA and HA-AGO2 or an empty vector was overexpressed, and total IRF3 and Ser386/Ser396-phosphorylated IRF3 in HEK293T cells were detected to determine whether the interaction between IRF3 and AGO2 affects stabilization and activation of IRF3. Figure 5A shows that VISA increased phosphorylation of IRF3, but AGO2 did not reduce the protein level of IRF3 nor affected IRF3 phosphorylation.

Although AGO2 did not suppress phosphorylation of IRF3, nuclear translocation following dimerization is also required for proper function of IRF3 (Yoneyama et al., 1998; Lin et al., 1999; Ysebrant de Lendonck et al., 2014). Flag-VISA and HAAGO2 or an empty vector was overexpressed in HEK293T cells, cytoplasm and nucleus were separated from cells, and western blots were performed to detect the distribution of total IRF3 and Ser386/Ser396 phosphorylated IRF3 in cells. The data showed that $\mathrm{AGO} 2$ did not affect nuclear translocation of IRF3 (Figure 5B). Collectively, these results indicated that AGO2 did not decrease protein level (or stability), Ser386/Ser396 phosphorylation, dimerization, and nuclear translocation of IRF3 but possibly inhibited some downstream events after activation of IRF3.

\section{AGO2 Does Not Affect DNA Binding Function of IRF3}

According to previous studies, IRF3 performs its function by binding to DNA, particularly to IFN stimulated response element (ISRE) sequence, which promotes transcription of 
A

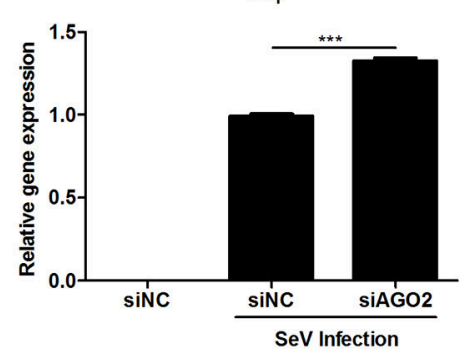

ISG-15

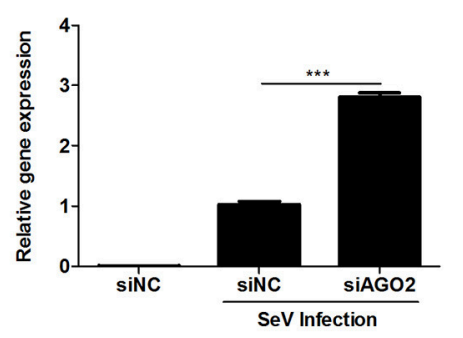

OAS1

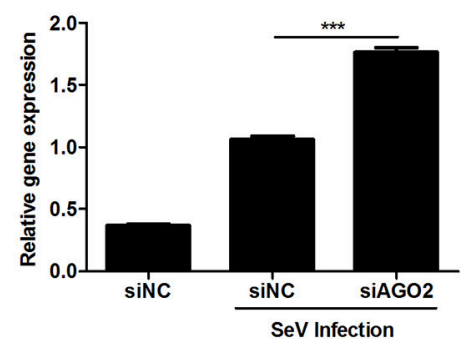

B

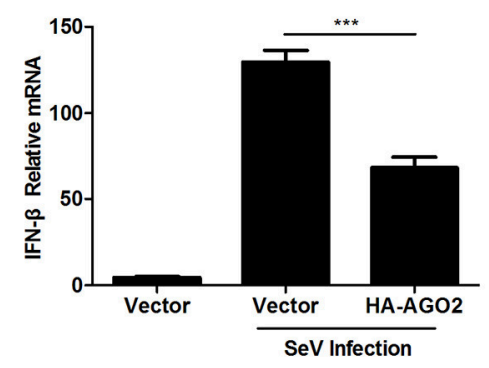

C

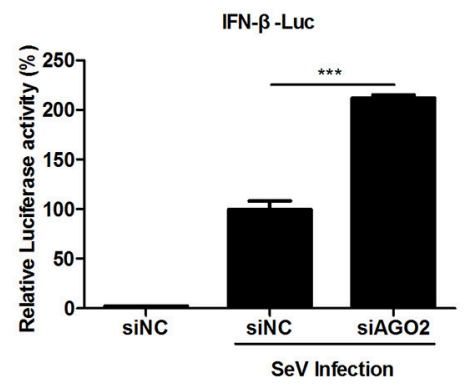

Mx1

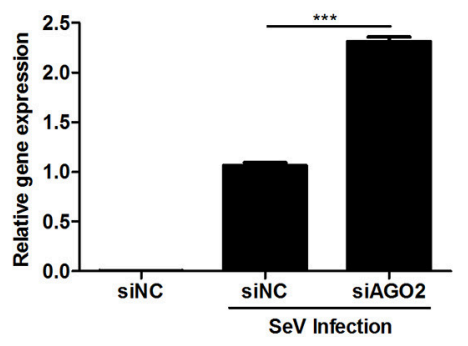

IFIT1

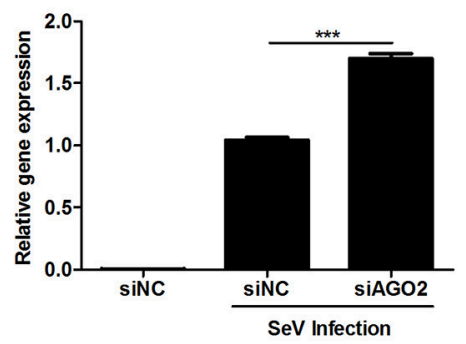

STAT1

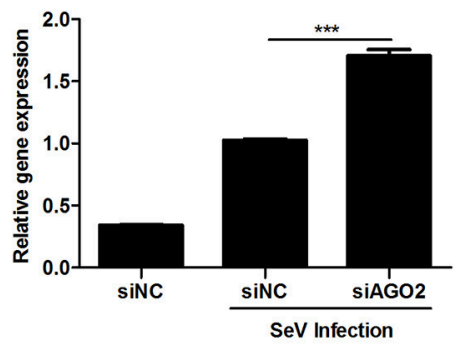

D

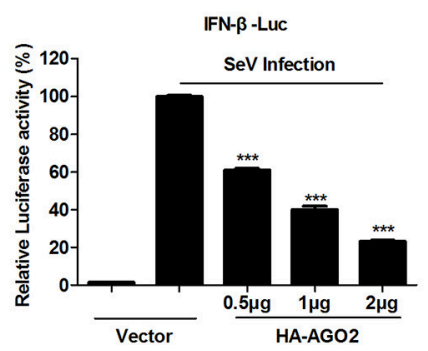

FIGURE 3 | AGO2 inhibits SeV induced IFN- $\beta$ activation. (A) A549 cells were transfected with siNC and siAGO2. After $48 \mathrm{~h}$, the cells were stimulated with SeV, and RNA expression levels of the ISGs and IFN- $\beta$ were compared. Data are presented as means \pm SD from three independent experiments. (B) A549 cells were 


\section{FIGURE 3 | Continued}

transfected with HA-AGO2 and an empty vector. After 48 h, the cells were stimulated with SeV, and the RNA expression levels of IFN- $\beta$ were examined. Data are presented as means \pm SD from three independent experiments. (C) HEK293T cells were cotransfected with siNC/siAGO2, IFN- $\beta$-Luc, and pGL4.75 (hRluc/CMV). After $48 \mathrm{~h}$, the cells were stimulated with SeV, and luciferase reporter assay was performed. Data are presented as means \pm SD from three independent experiments. (D) HEK293T cells were transfected with IFN- $\beta$-Luc and pGL4.75 hRluc/CMV together with increasing quantities of plasmids (i.e., 0.5, 1 , and $2 \mu \mathrm{g}$ ) encoding for AGO2. At $24 \mathrm{~h}$ post transfection, the cells were further infected with SeV or mock infected for $16 \mathrm{~h}$ before luciferase assays were performed. Data are presented as the means $\pm \mathrm{SD}$ from three independent experiments. ${ }^{\star \star \star} P<0.0001$, as determined by a $t$ test.
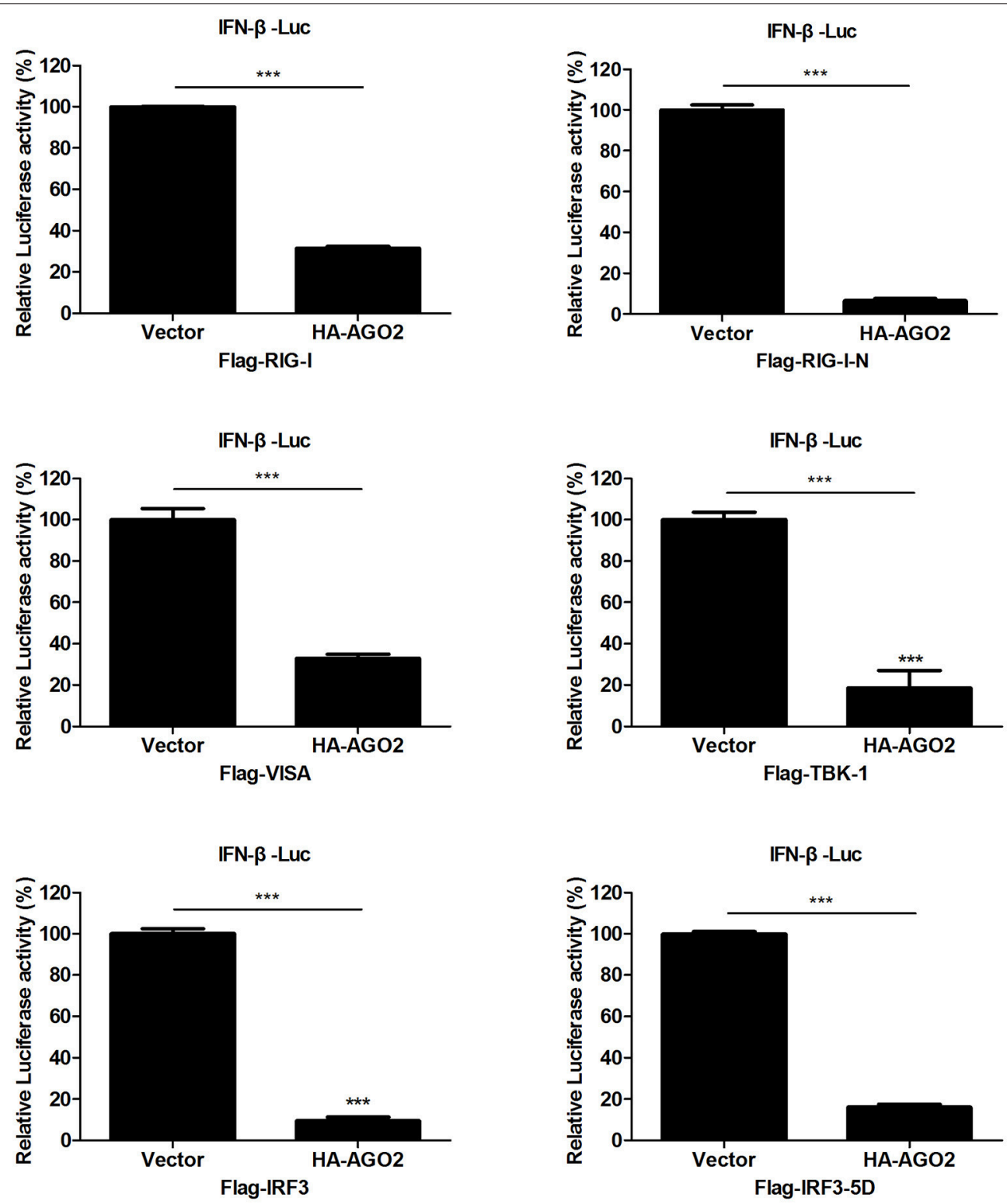

FIGURE 4 | AGO2 operates at or downstream of IRF3. HEK293T cells1 were transfected with IFN- $\beta$-Luc, pGL4.75 hRluc/CMV, HA-AGO2, or control plasmid, and Flag-RIG-I, Flag-RIG-I-N, Flag-VISA, Flag-TBK-1, Flag-IRF3, Flag-IRF3-5D, or control vectors. After 24 h, cells were collected, and relative luciferase activities were measured. Data are represented as mean \pm SD of three experiments. ${ }^{\star \star \star} P<0.0001$, as determined by a $t$ test.

IFN- $\beta$ gene (Weaver et al., 1998). DNA-binding assay was performed to investigate whether AGO2 can prevent this role of IRF3. HEK293T cells were initially transfected with plasmids expressing IRF3 in the absence or presence of AGO2 expression plasmids and were then infected with $\mathrm{SeV}$ at 24 $\mathrm{h}$ post transfection. Cell lysates were incubated after $12 \mathrm{~h}$ with either a native ISRE oligonucleotide, which can interact with activated IRF3 linked to streptavidin beads, or a mutated 
A

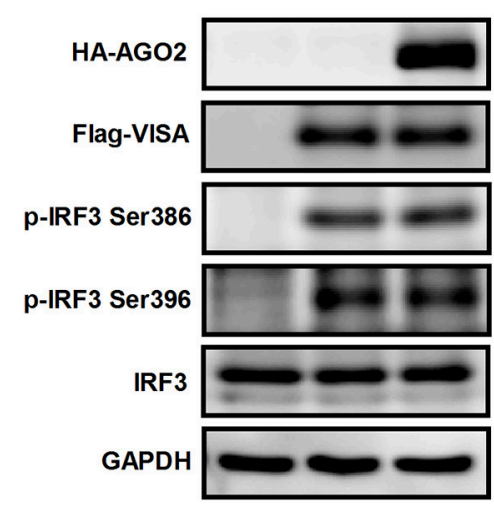

B

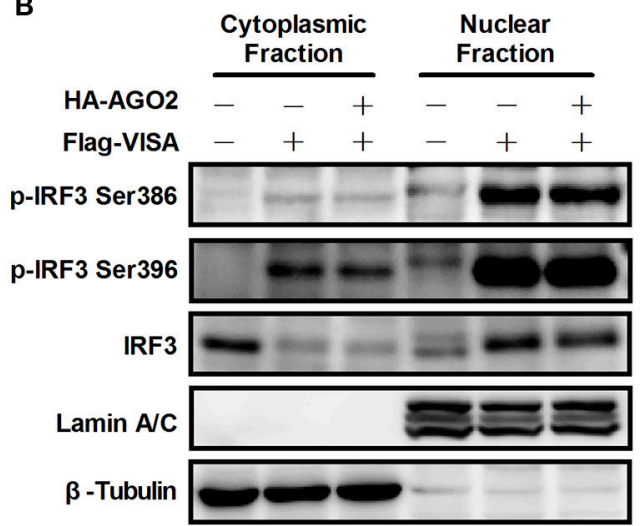

FIGURE 5 | AGO2 does not affect activation of IRF3. (A) HEK293T cells were transfected with Flag-VISA and HA-AGO2 with empty vectors as control. After 36 h, cells were lysed, and total IRF3 and Ser386/Ser396 phosphorylated forms of IRF3 were detected by western blot. (B) HEK293T cells were transfected with Flag-VISA and HA-AGO2 or empty vectors. After $36 \mathrm{~h}$, subcellular fractionation was implemented to separate the cytoplasm and nucleus from cells. Western blots were performed to detect distribution of total IRF3 and Ser386/Ser396 phosphorylated IRF3 in cells.

ISRE oligonucleotide, which cannot interact with activated IRF3 linked to the same beads. The beads were collected, and western blots were performed to detect bound IRF3 in ISRE oligonucleotides. Results indicated that AGO2 did not reduce the binding efficiency between IRF3 and ISRE (Figure 6).

\section{AGO2 Interacts with IRF3}

Previous studies showed that PACT and TRBP can interfere with IFN- $\beta$ signaling by interacting with signaling molecule RIG-I or PKR (Cosentino et al., 1995; Kok et al., 2011). Immunoprecipitation was performed with HEK293T cells cotransfected with HA-AGO2 and Flag-IRF3 or with Flag-AGO2 and HA-IRF3 to clarify the interaction between AGO2 and IRF3. Both experiments showed that AGO2 interacted with IRF3 (Figure 7A). HEK293T cells were stimulated with $\mathrm{SeV}$ for $3 \mathrm{~h}$, proteins were extracted, and anti-IRF3 antibody was used for immunoprecipitation. An endogenous interaction was detected afterward (Figure 7B). Immunofluorescence was also performed in HEK293T cells. IRF3 and AGO2 were co-localized under $\mathrm{SeV}$ infected and uninfected cell conditions and were strongly confocal at $\mathrm{SeV}$ infected cells (Figure 7C). Endogenous interaction and immunofluorescence was also performed in A549 cells (Figures 8A,B). Both results indicated that IRF3 interacted with AGO2.

\section{AGO2 Interferes with the Interaction between IRF3 and CBP/p300 by Interacting with C Terminus Domain of IRF3}

Given that AGO2 did not alter IRF3 phosphorylation, nuclear translocation, and DNA binding ability, AGO2 was hypothesized to play a role during assembly of IRF3 and CBP/p300 for the formation of transcriptional complex in the nucleus. Two vectors, namely, Flag-IRF3(1-197) containing DNA binding domain (DBD) and Flag-IRF3(198-427)/ Flag-IRF3-5D(198427) containing the IRF-3 activation domain (IAD), were constructed to examine the role of AGO2 in association of IRF3

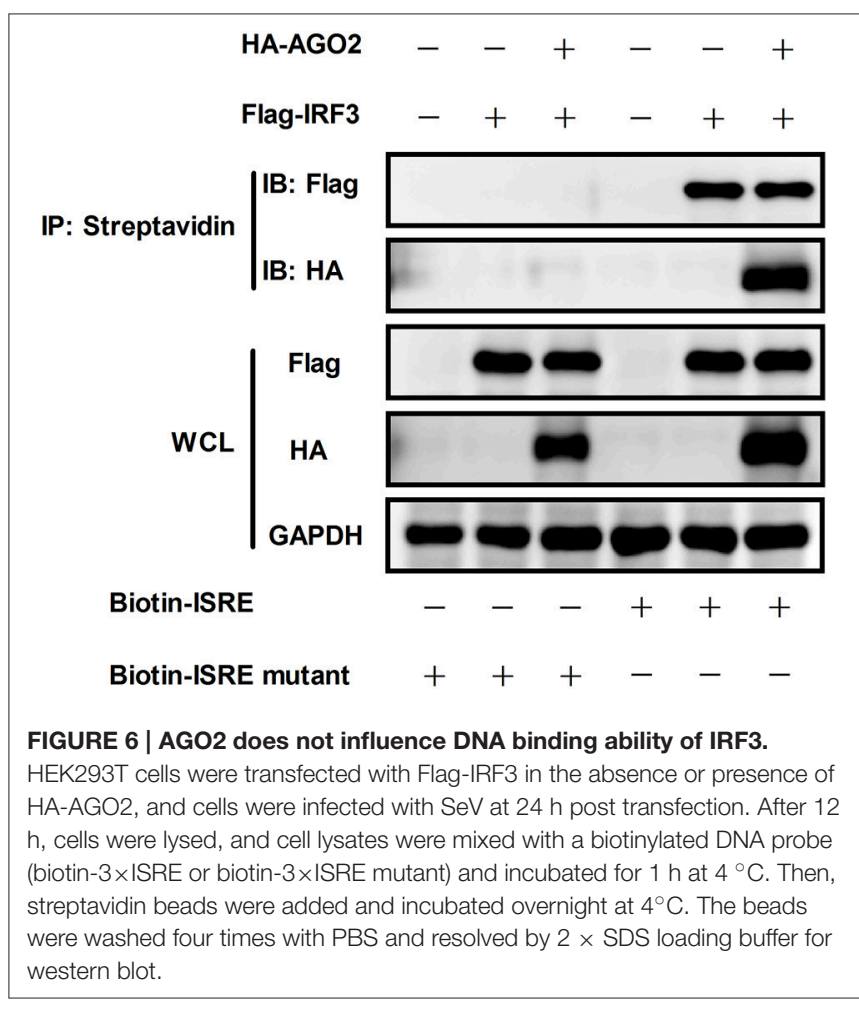

with CBP (Lin et al., 1999). Then, each vector was cotransfected with HA-AGO2 in HEK293T cells, and immunoprecipitation was performed. Results showed that AGO2 interacted with the IAD of IRF3/ IRF3-5D, which contains a region that interacted with IBiD (Lin et al., 1999, 2001), implying that AGO2 inhibited the interaction between IRF3 and CBP/p300 (Figure 9). A MycIBiD expression vector was constructed and cotransfected with Flag-IRF3 in the absence or presence of different concentrations of HA-AGO2 in HEK293T cells to investigate this hypothesis. 


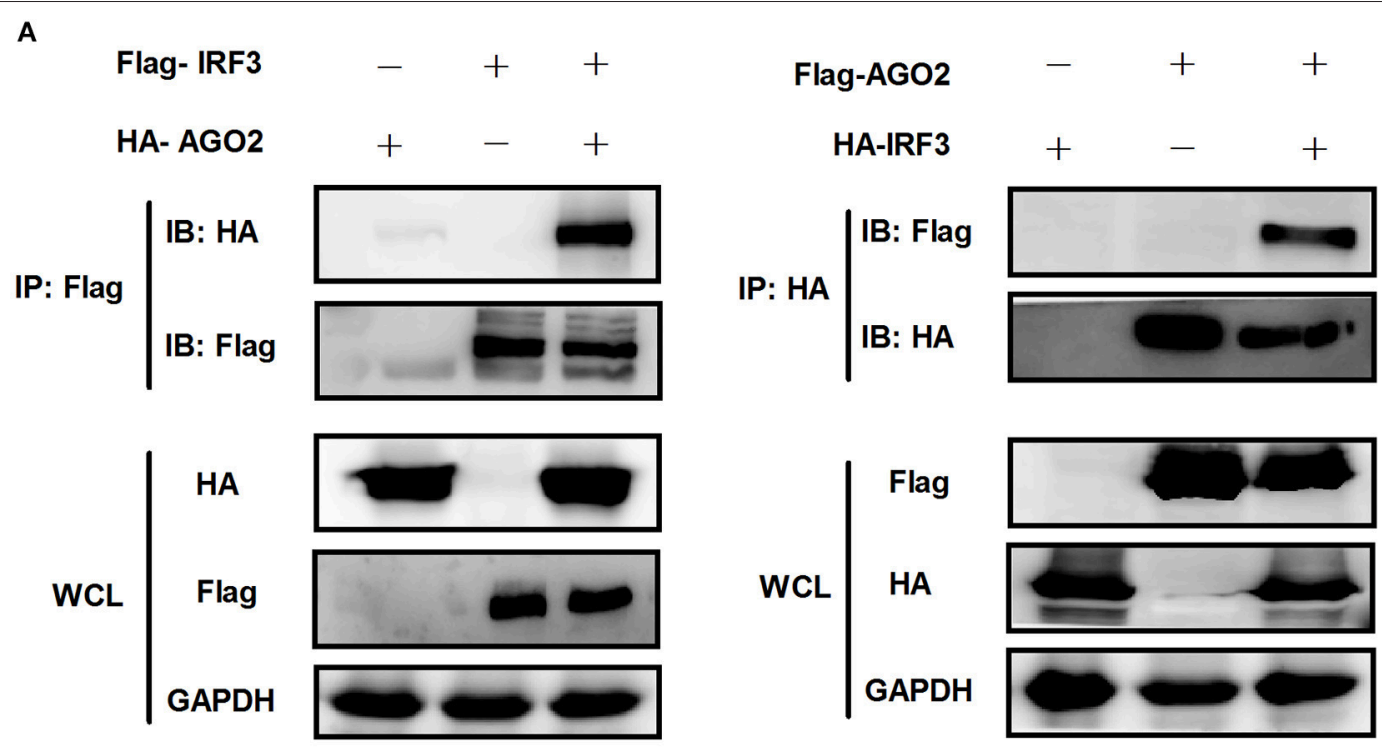

B

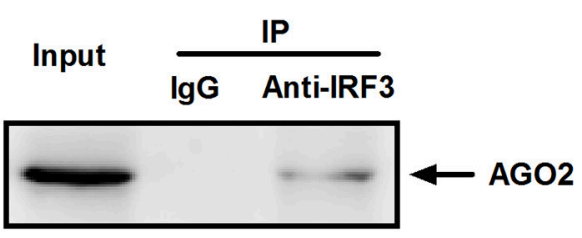

IB: IRF3

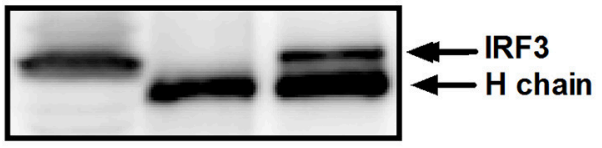

C
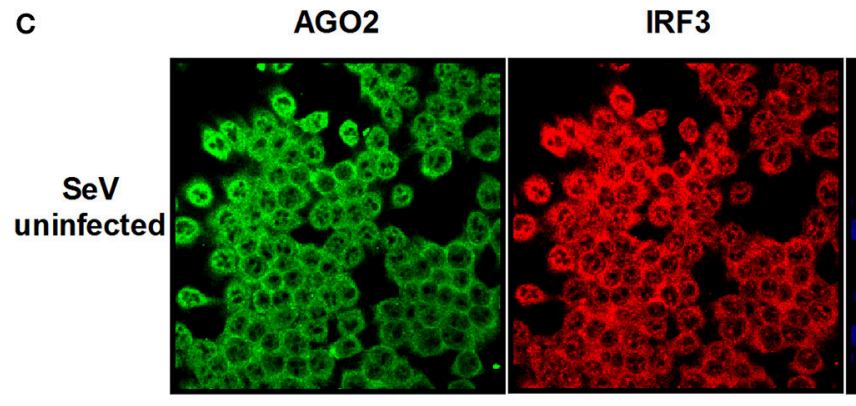

DAPI

Merge
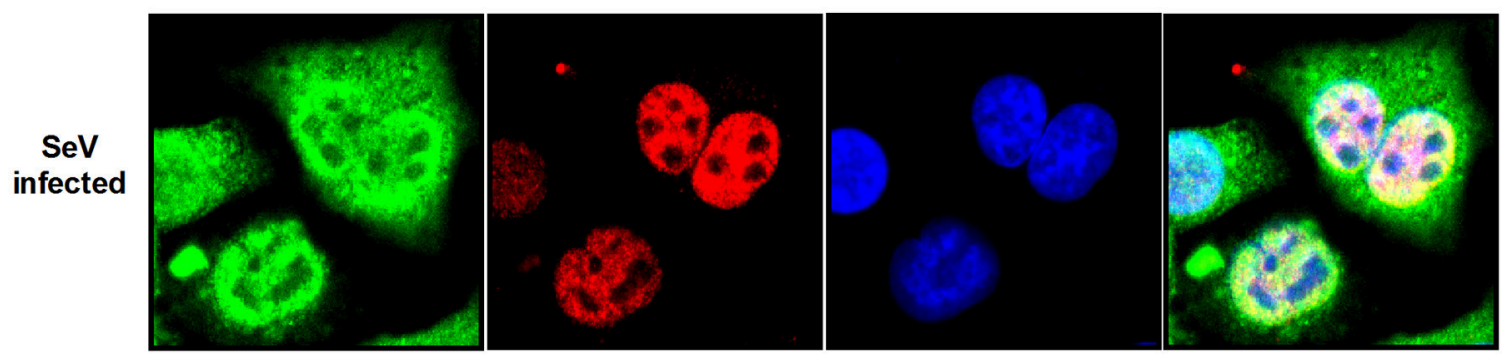

FIGURE 7 | AGO2 interacts with IRF3 in HEK293T cells. (A) HEK293T cells were transfected with HA-AGO2 and Flag-IRF3 or with Flag-AGO2 and HA-IRF3. After $36 \mathrm{~h}$, cells were lysed, and immunoprecipitation was performed. (B) HEK293T cells were stimulated with SeV for $3 \mathrm{~h}$, and cell proteins were extracted. Anti-IRF3 antibody was used for immunoprecipitation. (C) HEK293 cells were mock infected or infected with SeV. At $24 \mathrm{~h}$, subcellular localizations of IRF3 and AGO2 were visualized by immunofluorescence and microscopy. 
A

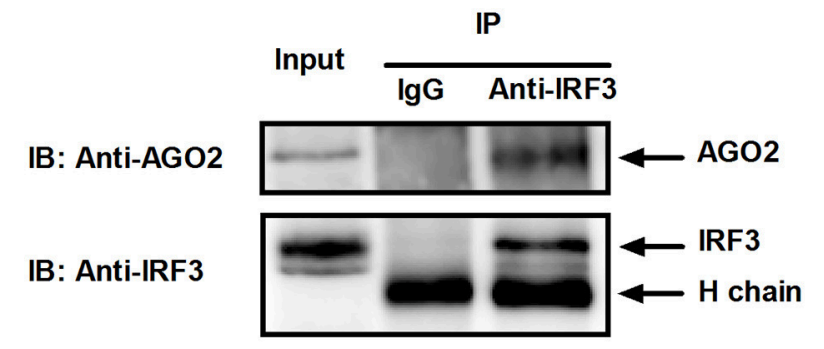

B

AGO2

IRF3

DAPI Merge
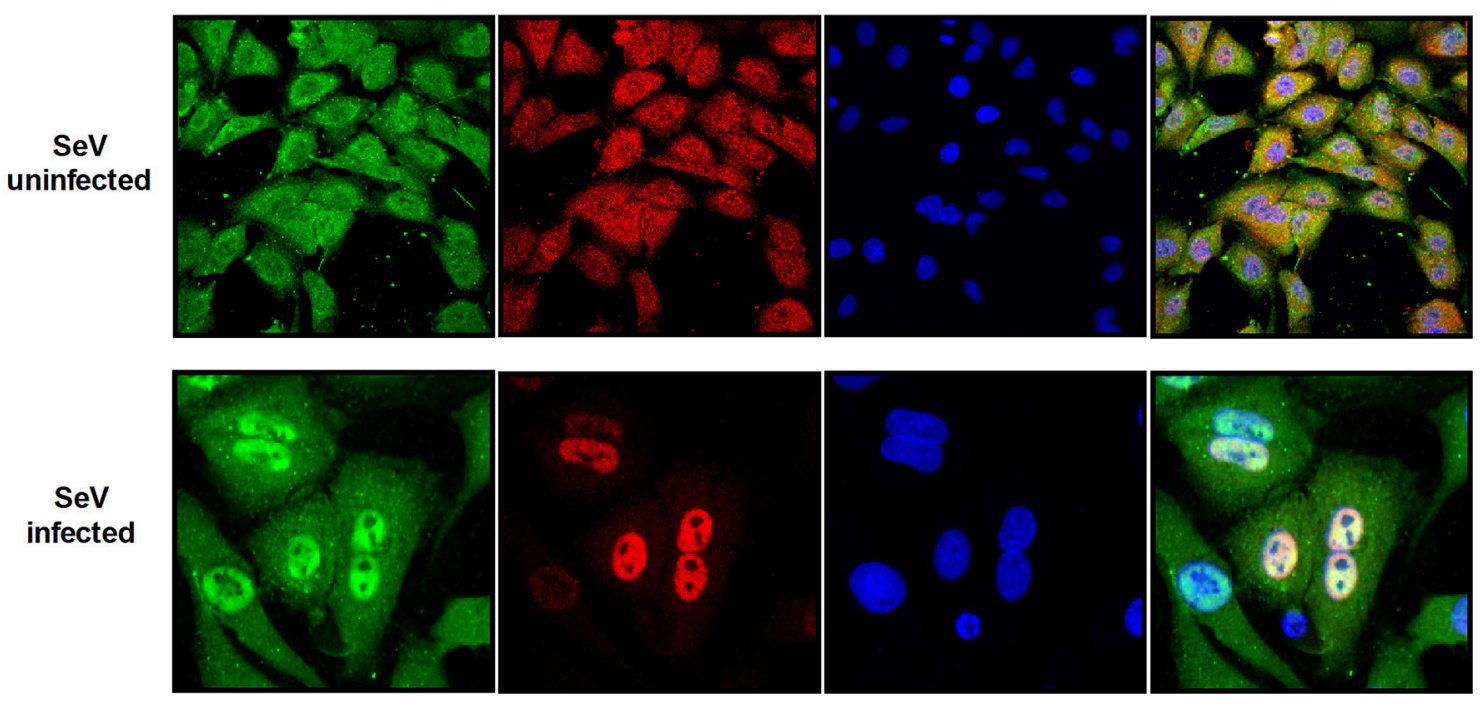

FIGURE 8 | AG02 interacts with IRF3 in A549 cells. (A) A549 cells were stimulated with SeV for 6 h, and cell proteins were extracted. Anti-IRF3 antibody was used for immunoprecipitation. (B) A549 cells were mock infected or infected with SeV. At 6 h, subcellular localizations of IRF3 and AGO2 were visualized by immunofluorescence and microscopy.

Then, immunoprecipitation was conducted, and results showed that AGO2 caused does-dependent inhibition of the interaction between IRF3 and IBiD (Figure 10A). Interaction of CBP with IRF3 and IRF3-5D with cotransfected HA-AGO2 in HEK293T cells was examined to verify further this phenomenon (Figure 10B). All results indicated that HA-AGO2 disturbed the interaction between IRF3 and CBP/p300.

\section{AGO2 Interacts with IRF3 by Its MID \\ Domain}

AGO2 contains four domains which are $\mathrm{N}$ domain, PAZ domain, MID domain and PIWI domain (Kuhn and JoshuaTor, 2013; Ye et al., 2015). We cloned this four domains into pCAGGS-HA expression vector. Then, each expression vector was cotransfected with Flag-IRF3 in HEK293T cells and immunoprecipitation was performed. Results showed that MID domain of AGO2 interact with IRF3 (Figure 11A). A MID domain deleted expression plasmid (HA-AGO2-MIDdel) was constructed and the interaction with IRF3 was examined. Result exhibited that HA-AGO2-MIDdel did not interact with IRF3 (Figure 11B) implying that HA-AGO2-MIDdel could not hinder the interaction between IRF3 and CBP. Interaction of CBP with IRF3 and IRF3-5D with cotransfected HAAGO2-MIDdel in HEK293T cells was examined to verify this assumption (Figure 11C). All results indicated that AGO2 negatively regulates type I interferon signaling pathway via competition binding IRF3 with CBP/p300.

\section{DISCUSSION}

Also known as eIF2C2, AGO2 belongs to the argonaute family, which participates in RNA-mediated gene silencing (RNAi) pathway (Ye et al., 2015). AGO2 also regulates multiple biological functions through protein-protein, protein-RNA, or proteinDNA interactions (Martinez and Gregory, 2013; Meister, 2013; Ye et al., 2015). Together with AGO2, SETDB1 plays an essential role in transcriptional gene silencing through recruitment of chromatin remodelers and/or other modifiers, consequently creating a repressive chromatin milieu at targeted promoters (Cho et al., 2014). AGO2 can directly bind to the promoter of focal adhesion kinase, which is a critical molecule associated with tumor metastasis, and can trigger its transcription (Cheng 
et al., 2013). AGO2 also acts as an RNA slicer independent of dicer and as regulator of miRNA maturation (Cifuentes et al., 2010; Ye et al., 2015). Previous studies showed that AGO2 can enhance miRNA stability (Winter and Diederichs, 2011; Ye et al., 2015). The functions of AGO2 remain to be understood. Initial discoveries indicated that this protein may participate in viral replication and type I IFN production in cells.

This study, investigated the influence of $\mathrm{AGO} 2$ on virus proliferation. Results showed that knockdown of AGO2

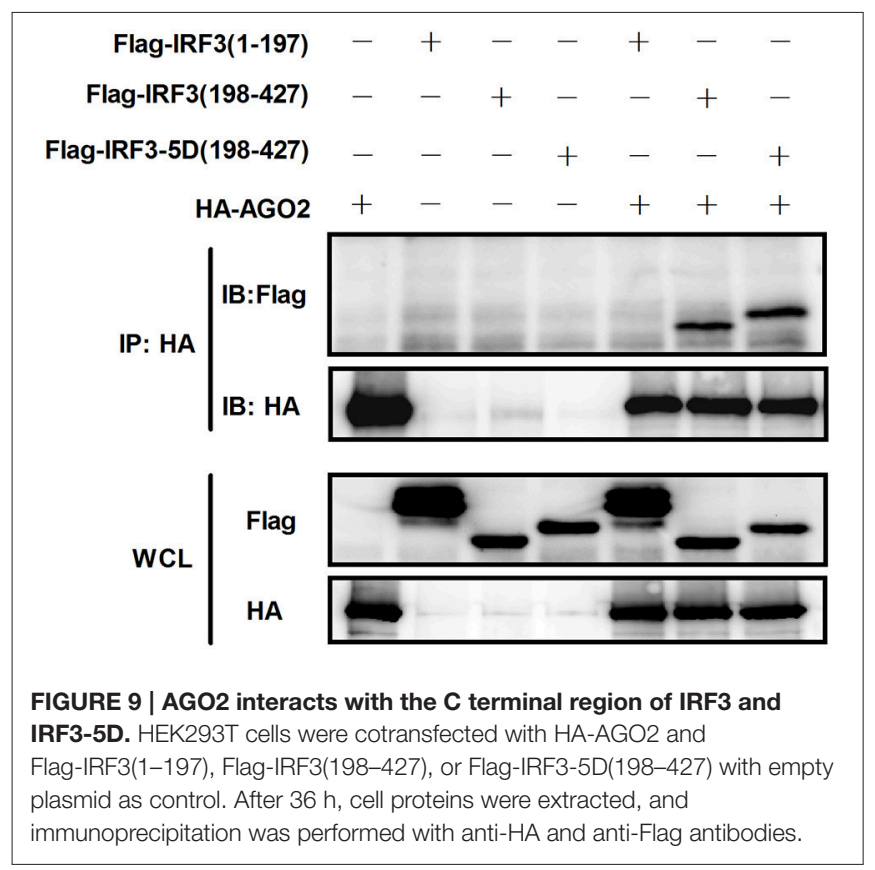

expression inhibited $\mathrm{H} 5 \mathrm{~N} 1$ virus replication, whereas its overexpression resulted in the opposite phenomenon (Figures 1B,C,E,F). This study also determined that viral infection can modify AGO2 distribution between cytoplasm and cell nucleus, and that it may influence virus/host interactions (Figures 2A,B). Therefore, AGO2 can directly influence innate immune responses and type I IFN signaling pathway. AGO2 was silenced, and expression level of ISGs and IFN- $\beta$ were detected to investigate this hypothesis. Results indicated that silencing of $\mathrm{AGO} 2$ promoted $\mathrm{SeV}$ induced expression levels of endogenous IFN- $\beta$, downstream IFIT1, and ISGs including Mx1, STAT1, and ISG15 (Figure 3A). The overexpression experiment involving A549 cells and double fluorescence reporting system in HEK293T cells also yielded the same results (Figures 3B-D). The targets of AGO2 inhibition in type I IFN signaling pathway were explored using double fluorescence reporting system in HEK293T cells. Notably, AGO2 suppressed activation of IFN- $\beta$ promoter, this action was mediated by overexpressions of RIG-I, RIG-I-N, VISA, TBK-1, IRF3, and IRF3-5D (Figure 4). These results indicated that AGO2 targeted at or downstream of IRF3 and negatively regulated activation of IFN- $\beta$ signaling.

Previous studies illustrated that activation of IRF3 is a key step for activation of IFN- $\beta$ signaling; IRF3 activation consists of phosphorylation, dimerization, and translocation to the nucleus (Servant et al., 2002; Chen et al., 2008; Takahasi et al., 2010; Ysebrant de Lendonck et al., 2014). Only phosphorylated IRF3 can dimerize and translocate to the nucleus (Lin et al., 1999). The most critical steps comprise phosphorylation and nuclear translocation. Thus, the effects of AGO2 on phosphorylation and nuclear translocation of IRF3 were analyzed using Western blot. Results proved that AGO2 did not prevent phosphorylation and nuclear translocation of IRF3 (Figures 5A,B). Ser339 also affects

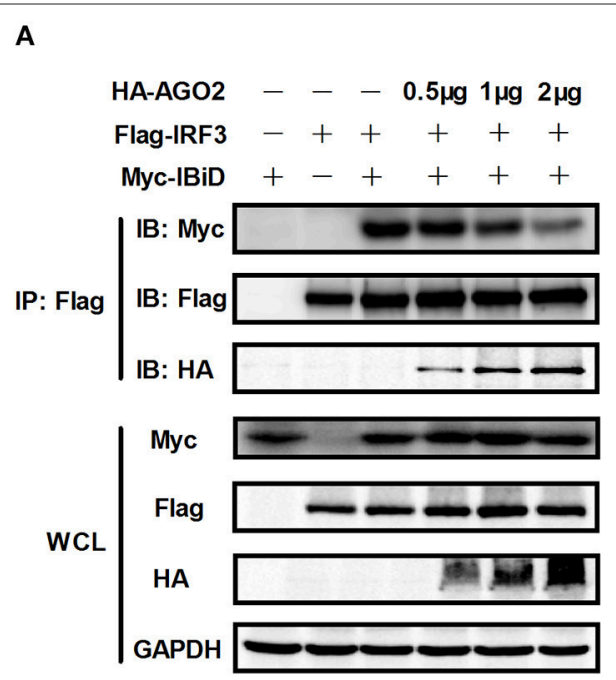

\section{B \\ B}

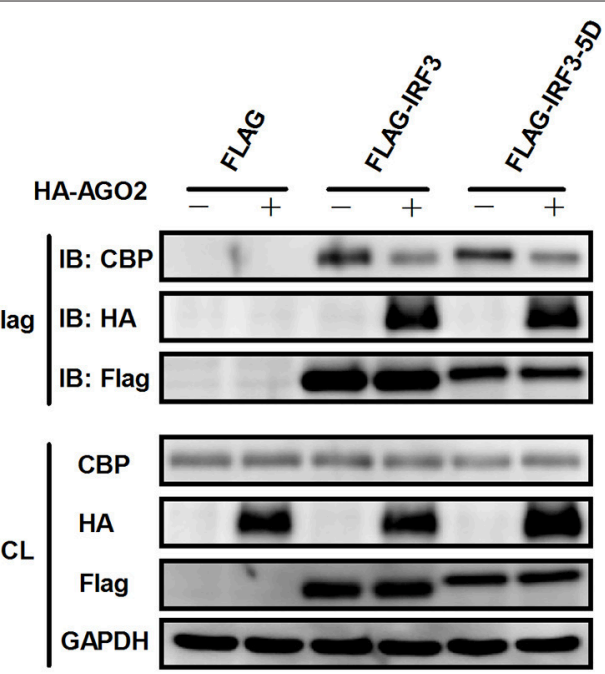

FIGURE 10 | AGO2 abolishes interaction between IRF3 and CBP/p300. (A) HEK293T cells were cotransfected with Myc-IBiD, Flag-IRF3, and different concentrations of HA-AGO2 (i.e., 0.5, 1, and $2 \mu \mathrm{g}$ ) with empty plasmid as control. After $36 \mathrm{~h}$, cells were stimulated by SeV for $12 \mathrm{~h}$, and cell proteins were extracted, and immunoprecipitation was performed with anti-HA, anti-Flag, and anti-Myc antibodies. (B) HEK293T cells were cotransfected with HA-AGO2 and Flag-IRF3 or Flag-IRF3-5D with empty vectors as control. After $36 \mathrm{~h}$, cells were stimulated by SeV for $12 \mathrm{~h}$, and cell lysates were immunoprecipitated with an anti-Flag antibody and immunoblotted with an anti-CBP antibody. 


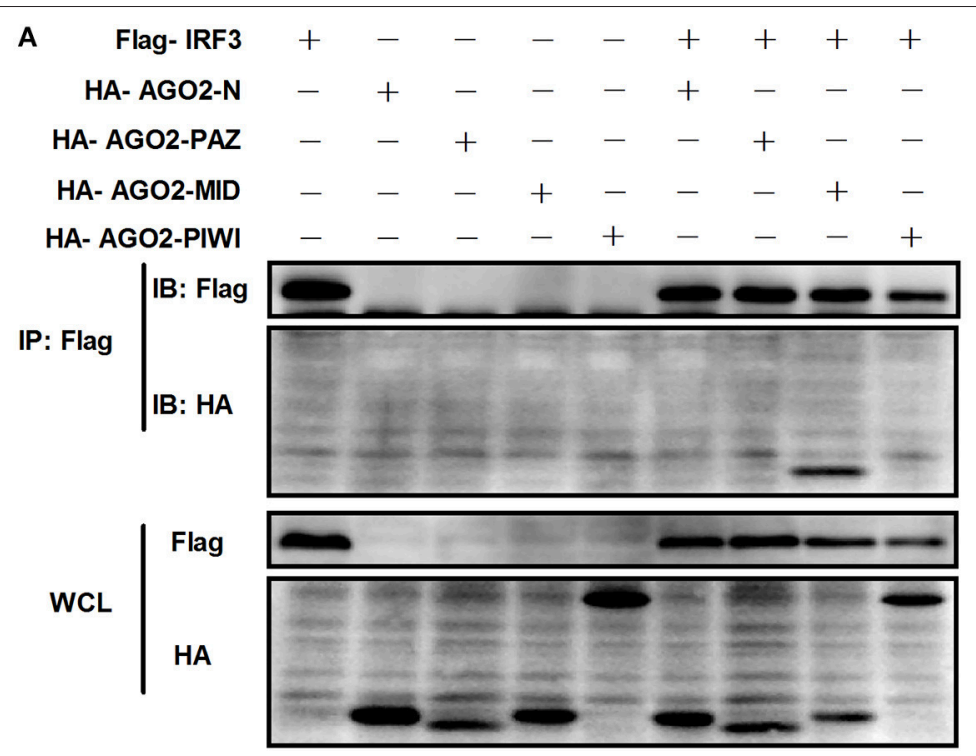

B

C

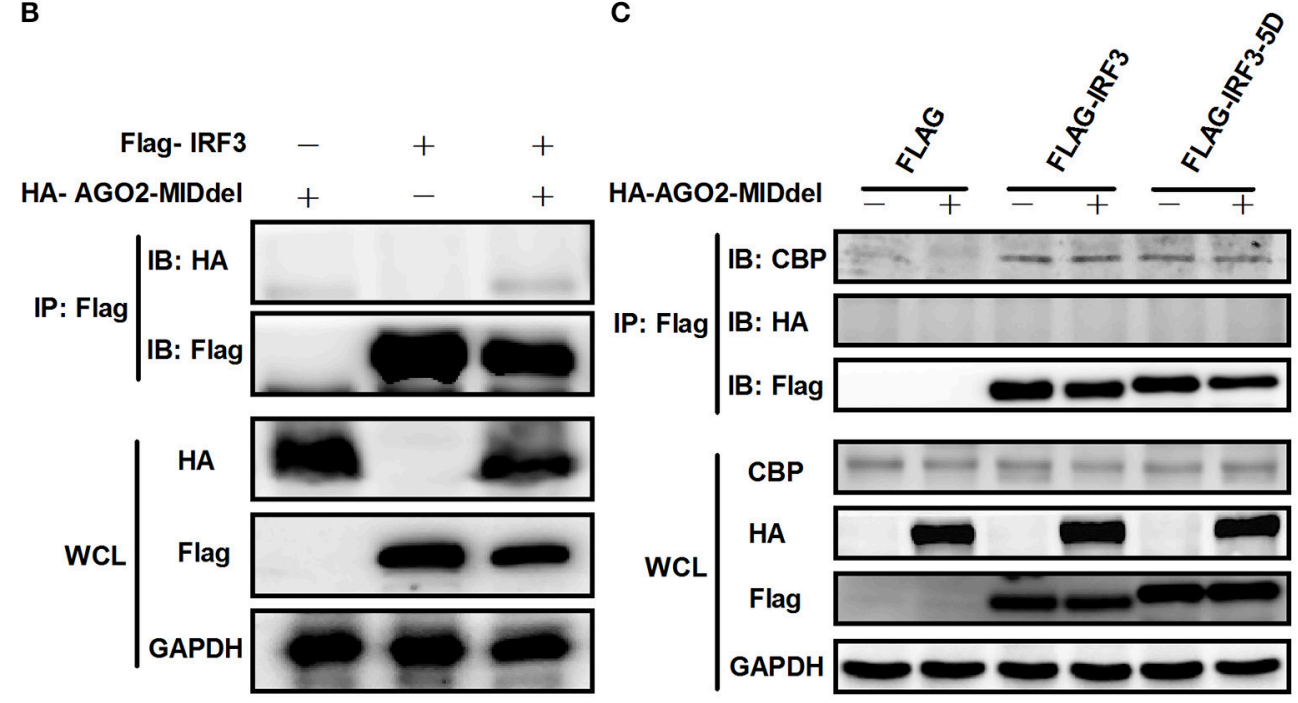

FIGURE 11 | AGO2 interacts with IRF3 by its MID domain. (A) HEK293T cells were co-transfected with four truncations of AGO2 and IRF3 and immunoprecipitation was performed at $36 \mathrm{~h}$ later. (B) The MID deleted mutation of AGO2 (HA-AGO2-MIDdel) and IRF3 were co-transfected into HEK293T cell. After 36 h, immunoprecipitation was performed. (C) HEK293T cells were co-transfected with HA-AGO2-MIDdel and Flag-IRF3 or Flag-IRF3-5D with empty vectors as control. After $36 \mathrm{~h}$, cells were stimulated by SeV for $12 \mathrm{~h}$ and cell lysates were immunoprecipitated with an anti-Flag antibody and immunoblotted with an anti-CBP antibody.

stability of IRF3 (Saitoh et al., 2006; Clement et al., 2008). Total IRF3 was also detected by western blot, and results showed that total IRF3 did not affected stability of IRF3 (Figure 5A). Binding of IRF3 to ISRE is also an important procedure, and DNA binding assay was performed (Ysebrant de Lendonck et al., 2014; Meng et al., 2016). Results indicated that AGO2 did not interfere with DNA binding ability of IRF3 (Figure 6). All results illustrated that AGO2 did not influence activation and DNA binding ability of IRF3.

Transcriptional coactivators associate with promoters and enhancers primarily through protein-protein contact, and mediate interactions between DNA-bound transcription factors and the general transcription machinery (Torchia et al., 1998; Gusterson et al., 2002; Tsuda et al., 2003). Transcriptional coactivators CBP and p300 are highly homologous and are critical regulators of metazoan gene expression, and interaction between IRF3 and $\mathrm{CBP} / \mathrm{p} 300$ play a significant role in transcriptional complex formation (Yoneyama et al., 1998; Suhara et al., 2002). CBP/p300 associates with many different DNA-bound transcription factors through small, conserved domains. A previous study identified a compactly folded 46residue domain (IBiD) in $\mathrm{CBP} / \mathrm{p} 300$ that can interact with IRF3 
at $\mathrm{C}$ terminal. IBiD is required for viral induction of IFN- $\beta$, and IBiD mutation causes loss of structural integrity of $\mathrm{CBP} / \mathrm{p} 300$ (Lin et al., 2001).

As AGO2 did not affect activation and DNA binding ability of IRF3 (Figure 6), interfering the formation of transcriptional complex which includes the interaction between IRF3 and $\mathrm{CBP} / \mathrm{p} 300$, bear significance (Yoneyama et al., 1998; Lin et al., 2001). Immunoprecipitation and immunofluorescence were conducted to understand the mechanisms underlying how AGO2 negatively regulates activation of IFN- $\beta$ signaling target at or downstream of IRF3. Results showed that AGO2 can interact with IRF3 (Figures 7A-C, 8A,B). Then, Flag-IRF3(1-197), which contains a DBD, and Flag-IRF3(198-427), which contains an IAD domain, were constructed. Each domain was cotransfected with HA-AGO2 in HEK293T cells, and immunoprecipitation was performed. The results indicated that AGO2 interacted with the IRF3 IAD while interacting with the domain associated with IBiD; AGO2 was speculated to interact with IRF3 to reduce IBiDIRF3 binding (Figure 9). Based on this assumption, Myc-IBiD was constructed and transfected with IRF3 in the absence or presence of HA-AGO2 expressing plasmid. Interaction between IRF3 and IBiD was detected by immunoprecipitation. The data showed that IBiD was dislodged from IRF3 as AGO2 was increased (Figure 10A). Interaction between IRF3/IRF3-5D and endogenous CBP was also detected in the absence or presence of HA-AGO2 expressing plasmid, further proving that AGO2 interfered with the interaction between IRF3 and CBP/p300 (Figure 10B). Therefore, AGO2 sequestered the interaction between IRF3 and CBP/p300. AGO2 contains four domain which is $\mathrm{N}$ domain, PAZ domain, MID domain, and PIWI domain (Kuhn and Joshua-Tor, 2013). We funded that MID domain interact with IRF3 and the deletion of MID domain could not abrogate interaction between IRF3 and CBP (Figures 11A,B). The competition binding essay also showed that AGO2-MIDdel could not hinder CBP/p300 binding to IRF3 (Figure 11C). This study provides insight into mechanisms underlying antagonism of IFN by AGO2.

This study, proposed a model in which virus-inducible activation of IRF3 interacts with coactivator $\mathrm{CBP} / \mathrm{p} 300$ and permits IRF3 primary activation of IFN- $\beta$ and IFN- $\beta$ responsive genes. This study also showed that $\mathrm{AGO} 2$ serves as a negative regulator, which suppresses IFN- $\beta$ and IFN $-\beta$ responsive genes by disturbing IRF3 binding to $\mathrm{CBP} / \mathrm{p} 300$, and that the interaction between IRF3 and AGO2 poses no influence on IRF3 DNA binding capacity. $\mathrm{H} 5 \mathrm{~N} 1$ can induce IFN- $\beta$ expression by decreasing nuclear AGO2 protein, which can inhibit IFN- $\beta$ expression in the nucleus (Figure 12).

AGO2 is a potential novel factor that maintains balance of in virus-induced type I IFN signaling pathway. This study also proposed a theory that cells can downregulate AGO2 content in the nucleus when stimulated by viruses, to induce inhibitory effects of $\mathrm{AGO} 2$ on IFN- $\beta$ expression and upregulate expression of IFN- $\beta$. Then, viruses can take advantage of inhibitory mechanisms of AGO2 to further propagate in cells. Previous studies showed that AGO2 and RNAi factors Dicer, TRBP, and TRNC6A/GW182 are located in the nucleus and associate together in multiprotein complexes (Gagnon et al., 2014). IPM8 is a regulator of AGO2, and knockdown of IPM8 reduces the nuclear AGO2 pool (Weinmann et al., 2009). The subcellular distribution of AGO2 during H5N1 infection depends on RNAi factors (Dicer, TRBP, and TRNC6A/GW182), IPM8 or other mechanisms, which

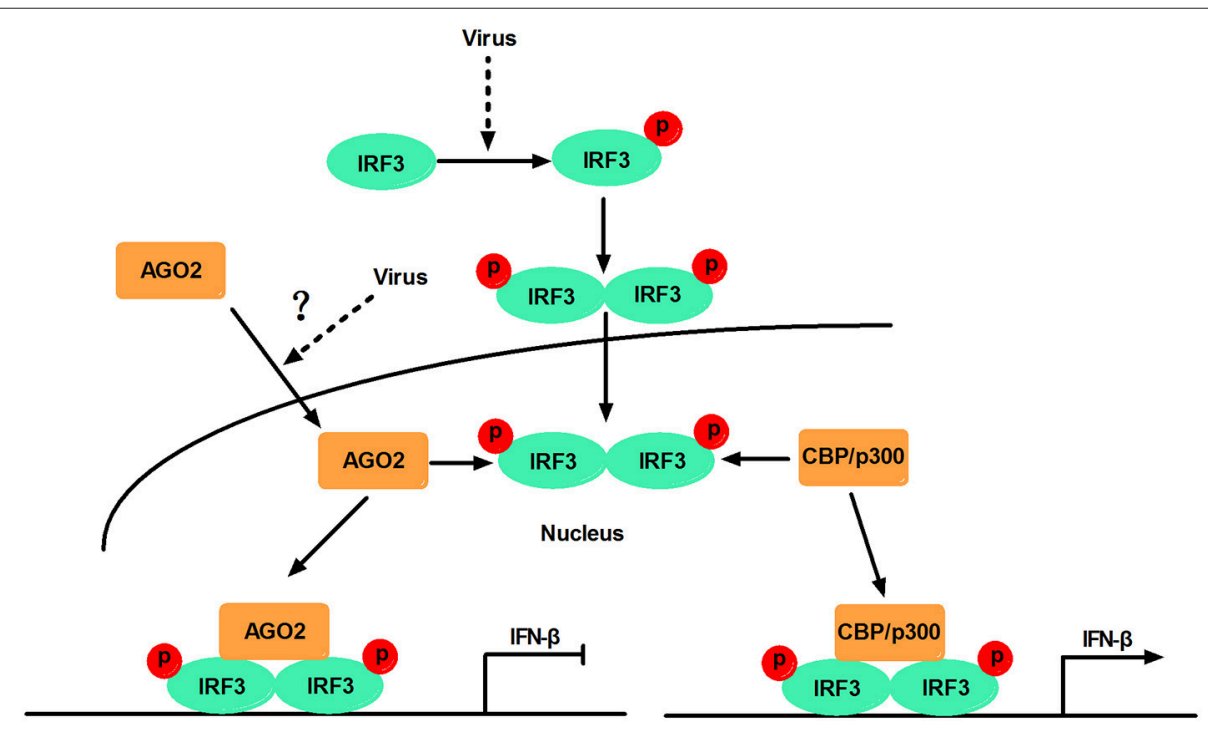

FIGURE 12 | Schematic diagram of AGO2 action on innate immune signaling pathway. Viral infection recruits kinases TBK-1 and IKK $\varepsilon$ to adaptor protein VISA and TRIF. These kinases phosphorylate IRF3, and phosphorylated IRF3 forms dimers that translocate into the nucleus and are activated. Activated IRF3 interacts with $\mathrm{CBP} / \mathrm{p} 300$, which forms the transcription initiation complex, and induces production of IFN- $\beta$. However, AGO2 inhibits IFN- $\beta$ promoter activation by interfering with IRF3-CBP interaction and represses formation of transcription initiation complex. H5N1 infection can reduce the distribution of AGO2 in the nucleus and further enhance IFN- $\beta$ promoter activation. 
should be further investigated. The proposed theory come and the observed phenomena will benefit prevention of virus infection.

\section{AUTHOR CONTRIBUTIONS}

MJ, HC, and SW conceived and designed the experiments; SW, XinS, CY, and DZ performed the experiments. SW and MJ analyzed the data; XinS, CY, XL, and XiaS contributed reagents/materials/analysis tools; SW wrote the paper. All authors have read and approved the final draft.

\section{REFERENCES}

Ahmad, S., and Hur, S. (2015). Helicases in antiviral immunity: dual properties as sensors and effectors. Trends Biochem. Sci. 40, 576-585. doi: 10.1016/j.tibs.2015.08.001

Akira, S., Uematsu, S., and Takeuchi, O. (2006). Pathogen recognition and innate immunity. Cell 124, 783-801. doi: 10.1016/j.cell.2006.02.015

Chen, W., Srinath, H., Lam, S. S., Schiffer, C. A., Royer, W. E. Jr., and Lin, K. (2008). Contribution of Ser386 and Ser396 to activation of interferon regulatory factor 3. J. Mol. Biol. 379, 251-260. doi: 10.1016/j.jmb.2008.03.050

Chendrimada, T. P., Finn, K. J., Ji, X., Baillat, D., Gregory, R. I., Liebhaber, S. A., et al. (2007). MicroRNA silencing through RISC recruitment of eIF6. Nature 447, 823-828. doi: 10.1038/nature05841

Chendrimada, T. P., Gregory, R. I., Kumaraswamy, E., Norman, J., Cooch, N., Nishikura, K., et al. (2005). TRBP recruits the Dicer complex to Ago2 for microRNA processing and gene silencing. Nature 436, 740-744. doi: $10.1038 /$ nature03868

Cheng, N., Li, Y., and Han, Z. G. (2013). Argonaute2 promotes tumor metastasis by way of up-regulating focal adhesion kinase expression in hepatocellular carcinoma. Hepatology 57, 1906-1918. doi: 10.1002/hep.26202

Chiang, J. J., Davis, M. E., and Gack, M. U. (2014). Regulation of RIG-I-like receptor signaling by host and viral proteins. Cytokine Growth Factor Rev. 25, 491-505. doi: 10.1016/j.cytogfr.2014.06.005

Cho, S., Park, J. S., and Kang, Y. K. (2014). AGO2 and SETDB1 cooperate in promoter-targeted transcriptional silencing of the androgen receptor gene. Nucleic Acids Res. 42, 13545-13556. doi: 10.1093/nar/gku788

Cifuentes, D., Xue, H., Taylor, D. W., Patnode, H., Mishima, Y., Cheloufi, S., et al. (2010). A novel miRNA processing pathway independent of Dicer requires Argonaute2 catalytic activity. Science 328, 1694-1698. doi: 10.1126/science.1190809

Clement, J. F., Bibeau-Poirier, A., Gravel, S. P., Grandvaux, N., Bonneil, E., Thibault, P., et al. (2008). Phosphorylation of IRF-3 on Ser 339 generates a hyperactive form of IRF-3 through regulation of dimerization and CBP association. J. Virol. 82, 3984-3996. doi: 10.1128/JVI.02526-07

Cosentino, G. P., Venkatesan, S., Serluca, F. C., Green, S. R., Mathews, M. B., and Sonenberg, N. (1995). Double-stranded-RNA-dependent protein kinase and TAR RNA-binding protein form homo- and heterodimers in vivo. Proc. Natl. Acad. Sci. U.S.A. 92, 9445-9449. doi: 10.1073/pnas.92.21.9445

Gagnon, K. T., Li, L., Chu, Y., Janowski, B. A., and Corey, D. R. (2014). RNAi factors are present and active in human cell nuclei. Cell Rep. 6, 211-221. doi: 10.1016/j.celrep.2013.12.013

Gilliet, M., Cao, W., and Liu, Y. J. (2008). Plasmacytoid dendritic cells: sensing nucleic acids in viral infection and autoimmune diseases. Nat. Rev. Immunol. 8, 594-606. doi: 10.1038/nri2358

Gonzalez-Navajas, J. M., Lee, J., David, M., and Raz, E. (2012). Immunomodulatory functions of type I interferons. Nat. Rev. Immunol. 12, 125-135. doi: $10.1038 /$ nri3133

Goubau, D., Deddouche, S., and Reis E Sousa, C. (2013). Cytosolic sensing of viruses. Immunity 38, 855-869. doi: 10.1016/j.immuni.2013.05.007

\section{FUNDING}

This work was supported by National Key Research and Development Program of China (No. 2016YFD0500205) and National Key Research and Development Program of China (No. 2017YFD0501600).

\section{ACKNOWLEDGMENTS}

We thank Zhengfan Jiang (Peking University) for providing Flag-RIG-I, Flag-VISA, Flag-TBK-1, and HA-IRF3 expression plasmid.

Gough, D. J., Messina, N. L., Clarke, C. J., Johnstone, R. W., and Levy, D. E. (2012). Constitutive type I interferon modulates homeostatic balance through tonic signaling. Immunity 36, 166-174. doi: 10.1016/j.immuni.2012.01.011

Gusterson, R., Brar, B., Faulkes, D., Giordano, A., Chrivia, J., and Latchman, D. (2002). The transcriptional co-activators CBP and p300 are activated via phenylephrine through the p42/p44 MAPK cascade. J. Biol. Chem. 277, 2517-2524. doi: 10.1074/jbc.M104626200

Hock, J., and Meister, G. (2008). The Argonaute protein family. Genome Biol. 9:210. doi: 10.1186/gb-2008-9-2-210

Ivashkiv, L. B., and Donlin, L. T. (2014). Regulation of type I interferon responses. Nat. Rev. Immunol. 14, 36-49. doi: 10.1038/nri3581

Katze, M. G., Fornek, J. L., Palermo, R. E., Walters, K. A., and Korth, M. J. (2008). Innate immune modulation by RNA viruses: emerging insights from functional genomics. Nat. Rev. Immunol. 8, 644-654. doi: 10.1038/nri2377

Kim, Y., Yeo, J., Lee, J. H., Cho, J., Seo, D., Kim, J. S., et al. (2014). Deletion of human tarbp2 reveals cellular microRNA targets and cell-cycle function of TRBP. Cell Rep. 9, 1061-1074. doi: 10.1016/j.celrep.2014.09.039

Kiriakidou, M., Tan, G. S., Lamprinaki, S., De Planell-Saguer, M., Nelson, P. T., and Mourelatos, Z. (2007). An mRNA m7G cap binding-like motif within human Ago2 represses translation. Cell 129, 1141-1151. doi: 10.1016/j.cell.2007.05.016

Kok, K. H., Lui, P. Y., Ng, M. H., Siu, K. L., Au, S. W., and Jin, D. Y. (2011). The double-stranded RNA-binding protein PACT functions as a cellular activator of RIG-I to facilitate innate antiviral response. Cell Host Microbe 9, 299-309. doi: 10.1016/j.chom.2011.03.007

Kuhn, C. D., and Joshua-Tor, L. (2013). Eukaryotic Argonautes come into focus. Trends Biochem. Sci. 38, 263-271. doi: 10.1016/j.tibs.2013.02.008

Lin, C. H., Hare, B. J., Wagner, G., Harrison, S. C., Maniatis, T., and Fraenkel, E. (2001). A small domain of CBP/p300 binds diverse proteins: solution structure and functional studies. Mol. Cell 8, 581-590. doi: 10.1016/S1097-2765(01)00333-1

Lin, R., Heylbroeck, C., Pitha, P. M., and Hiscott, J. (1998). Virusdependent phosphorylation of the IRF-3 transcription factor regulates nuclear translocation, transactivation potential, and proteasome-mediated degradation. Mol. Cell. Biol. 18, 2986-2996. doi: 10.1128/MCB.18.5.2986

Lin, R., Mamane, Y., and Hiscott, J. (1999). Structural and functional analysis of interferon regulatory factor 3: localization of the transactivation and autoinhibitory domains. Mol. Cell. Biol. 19, 2465-2474. doi: 10.1128/MCB.19.4.2465

Martinez, N. J., and Gregory, R. I. (2013). Argonaute2 expression is posttranscriptionally coupled to microRNA abundance. RNA 19, 605-612. doi: 10.1261/rna.036434.112

Matskevich, A. A., and Moelling, K. (2007). Dicer is involved in protection against influenza A virus infection. J. Gen. Virol. 88, 2627-2635. doi: 10.1099/vir.0.83103-0

Meister, G. (2013). Argonaute proteins: functional insights and emerging roles. Nat. Rev. Genet. 14, 447-459. doi: 10.1038/nrg3462

Meng, F., Zhou, R., Wu, S., Zhang, Q., Jin, Q., Zhou, Y., et al. (2016). Mst1 shuts off cytosolic antiviral defense through IRF3 phosphorylation. Genes Dev. 30, 1086-1100. doi: 10.1101/gad.277533.116 
Mori, M., Yoneyama, M., Ito, T., Takahashi, K., Inagaki, F., and Fujita, T. (2004). Identification of Ser-386 of interferon regulatory factor 3 as critical target for inducible phosphorylation that determines activation. J. Biol. Chem. 279, 9698-9702. doi: 10.1074/jbc.M310616200

Moshkovich, N., Nisha, P., Boyle, P. J., Thompson, B. A., Dale, R. K., and Lei, E. P. (2011). RNAi-independent role for Argonaute2 in CTCF/CP190 chromatin insulator function. Genes Dev. 25, 1686-1701. doi: 10.1101/gad.16651211

Ramakrishnan, M. A. (2016). Determination of $50 \%$ endpoint titer using a simple formula. World J. Virol. 5, 85-86. doi: 10.5501/wjv.v5.i2.85

Reily, M. M., Pantoja, C., Hu, X., Chinenov, Y., and Rogatsky, I. (2006). The GRIP1:IRF3 interaction as a target for glucocorticoid receptor-mediated immunosuppression. EMBO J. 25, 108-117. doi: 10.1038/sj.emboj.7600919

Saitoh, T., Tun-Kyi, A., Ryo, A., Yamamoto, M., Finn, G., Fujita, T., et al. (2006). Negative regulation of interferon-regulatory factor 3-dependent innate antiviral response by the prolyl isomerase Pin1. Nat. Immunol. 7, 598-605. doi: $10.1038 /$ ni1347

Servant, M. J., Grandvaux, N., and Hiscott, J. (2002). Multiple signaling pathways leading to the activation of interferon regulatory factor 3. Biochem. Pharmacol. 64, 985-992. doi: 10.1016/S0006-2952(02)01165-6

Servant, M. J., Grandvaux, N., Tenoever, B. R., Duguay, D., Lin, R., and Hiscott, J. (2003). Identification of the minimal phosphoacceptor site required for in vivo activation of interferon regulatory factor 3 in response to virus and doublestranded RNA. J. Biol. Chem. 278, 9441-9447. doi: 10.1074/jbc.M209851200

Servant, M. J., Ten Oever, B., Lepage, C., Conti, L., Gessani, S., Julkunen, I., et al. (2001). Identification of distinct signaling pathways leading to the phosphorylation of interferon regulatory factor 3. J. Biol. Chem. 276, 355-363. doi: 10.1074/jbc.M007790200

Song, S., Lee, J. J., Kim, H. J., Lee, J. Y., Chang, J., and Lee, K. J. (2016). Fasassociated factor 1 negatively regulates the antiviral immune response by inhibiting translocation of interferon regulatory factor 3 to the nucleus. Mol. Cell. Biol. 36, 1136-1151. doi: 10.1128/MCB.00744-15

Suhara, W., Yoneyama, M., Kitabayashi, I., and Fujita, T. (2002). Direct involvement of CREB-binding protein/p300 in sequencespecific DNA binding of virus-activated interferon regulatory factor-3 holocomplex. J. Biol. Chem. 277, 22304-22313. doi: 10.1074/jbc.M2001 92200

Takahasi, K., Horiuchi, M., Fujii, K., Nakamura, S., Noda, N. N., Yoneyama, M., et al. (2010). Ser386 phosphorylation of transcription factor IRF-3 induces dimerization and association with $\mathrm{CBP} / \mathrm{p} 300$ without overall conformational change. Genes Cells 15, 901-910. doi: 10.1111/j.1365-2443.2010. 01427.x

Torchia, J., Glass, C., and Rosenfeld, M. G. (1998). Co-activators and co-repressors in the integration of transcriptional responses. Curr. Opin. Cell Biol. 10, 373-383. doi: 10.1016/S0955-0674(98)80014-8

Tsuda, M., Takahashi, S., Takahashi, Y., and Asahara, H. (2003). Transcriptional co-activators CREB-binding protein and p300 regulate chondrocyte-specific gene expression via association with Sox9. J. Biol. Chem. 278, 27224-27229. doi: 10.1074/jbc.M303471200
Vasudevan, S., and Steitz, J. A. (2007). AU-rich-element-mediated upregulation of translation by FXR1 and Argonaute 2. Cell 128, 1105-1118. doi: 10.1016/j.cell.2007.01.038

Wang, P., Zhao, W., Zhao, K., Zhang, L., and Gao, C. (2015). TRIM26 negatively regulates interferon-beta production and antiviral response through polyubiquitination and degradation of nuclear IRF3. PLoS Pathog. 11:e1004726. doi: 10.1371/journal.ppat.1004726

Weaver, B. K., Kumar, K. P., and Reich, N. C. (1998). Interferon regulatory factor 3 and CREB-binding protein/p300 are subunits of double-stranded RNA-activated transcription factor DRAF1. Mol. Cell. Biol. 18, 1359-1368. doi: 10.1128/MCB.18.3.1359

Weinmann, L., Hock, J., Ivacevic, T., Ohrt, T., Mutze, J., Schwille, P., et al. (2009). Importin 8 is a gene silencing factor that targets argonaute proteins to distinct mRNAs. Cell 136, 496-507. doi: 10.1016/j.cell.2008.12.023

Winter, J., and Diederichs, S. (2011). Argonaute proteins regulate microRNA stability: increased microRNA abundance by Argonaute proteins is due to microRNA stabilization. RNA Biol. 8, 1149-1157. doi: 10.4161/rna.8.6.17665

$\mathrm{Wu}$, J., and Chen, Z. J. (2014). Innate immune sensing and signaling of cytosolic nucleic acids. Annu. Rev. Immunol. 32, 461-488. doi: 10.1146/annurev-immunol-032713-120156

Ye, Z., Jin, H., and Qian, Q. (2015). Argonaute 2: a novel rising star in cancer research. J. Cancer 6, 877-882. doi: 10.7150/jca.11735

Yoneyama, M., Kikuchi, M., Matsumoto, K., Imaizumi, T., Miyagishi, M., Taira, K., et al. (2005). Shared and unique functions of the DExD/H-box helicases RIG-I, MDA5, and LGP2 in antiviral innate immunity. J. Immunol. 175, 2851-2858. doi: 10.4049/jimmunol.175.5.2851

Yoneyama, M., Suhara, W., Fukuhara, Y., Fukuda, M., Nishida, E., and Fujita T. (1998). Direct triggering of the type I interferon system by virus infection: activation of a transcription factor complex containing IRF-3 and CBP/p300. EMBO J. 17, 1087-1095. doi: 10.1093/emboj/17.4.1087

You, F., Sun, H., Zhou, X., Sun, W., Liang, S., Zhai, Z., et al. (2009). PCBP2 mediates degradation of the adaptor MAVS via the HECT ubiquitin ligase AIP4 Nat. Immunol. 10, 1300-1308. doi: 10.1038/ni.1815

Ysebrant de Lendonck, L., Martinet, V., and Goriely, S. (2014). Interferon regulatory factor 3 in adaptive immune responses. Cell. Mol. Life Sci. 71, 3873-3883. doi: 10.1007/s00018-014-1653-9

Conflict of Interest Statement: The authors declare that the research was conducted in the absence of any commercial or financial relationships that could be construed as a potential conflict of interest.

Copyright (c) 2017 Wang, Sun, Yi, Zhang, Lin, Sun, Chen and Jin. This is an openaccess article distributed under the terms of the Creative Commons Attribution License (CC BY). The use, distribution or reproduction in other forums is permitted, provided the original author(s) or licensor are credited and that the original publication in this journal is cited, in accordance with accepted academic practice. No use, distribution or reproduction is permitted which does not comply with these terms. 